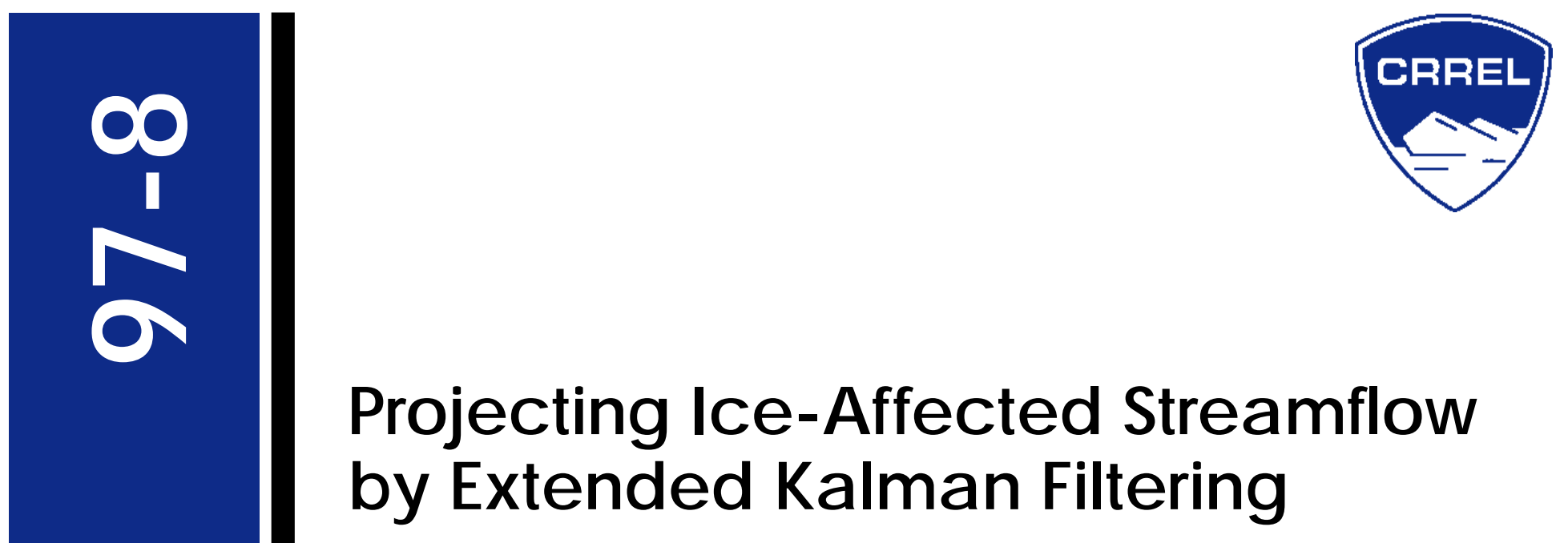

David J . Holtschlag, Charles T. Parker, and MohinderS. Grewal

December 1997
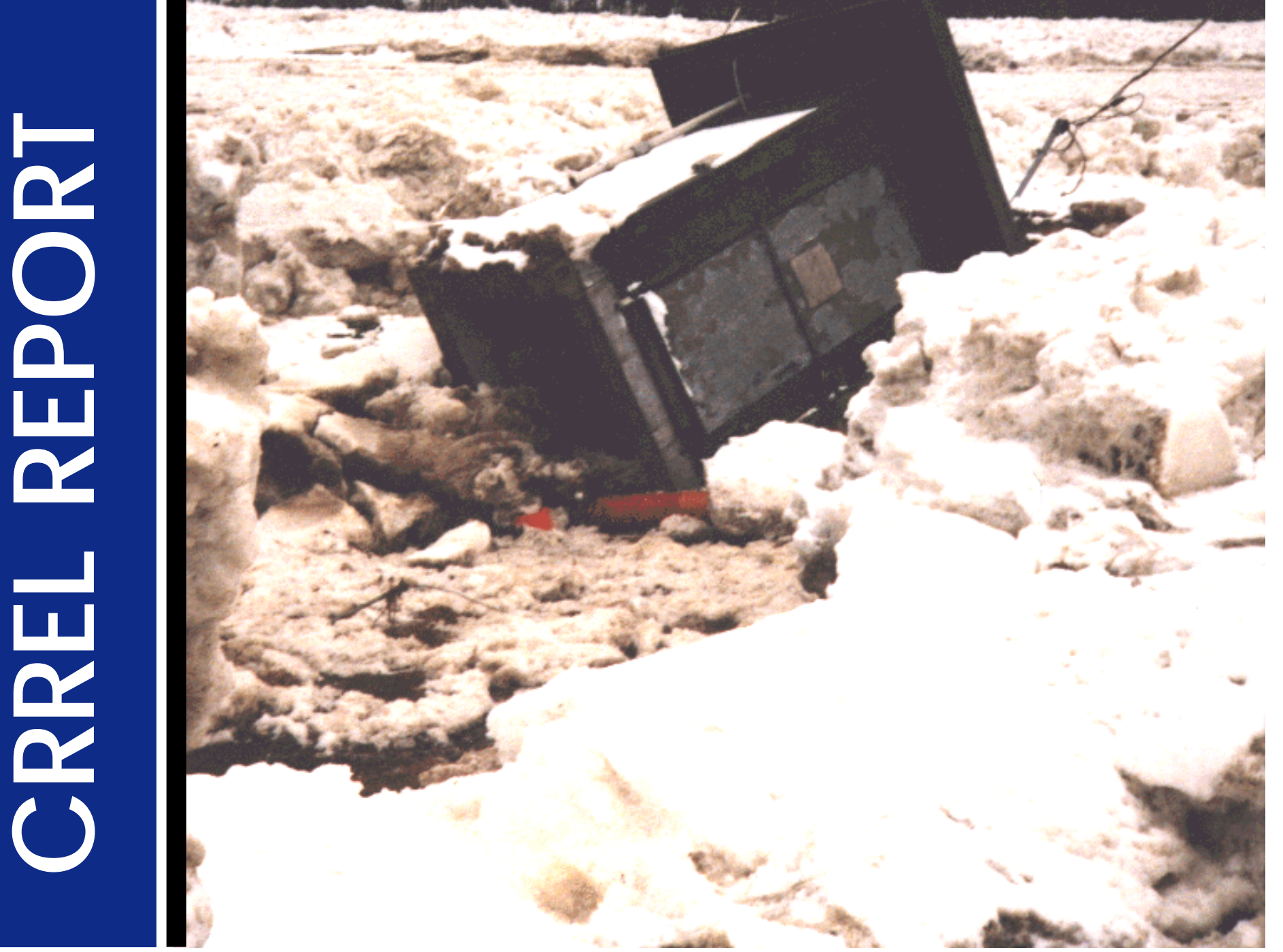
Abstract: An extended Kalman filter was developed to automate the real-time projection of ice-affected streamflow, based on routine measurements of stage and air temperature and the relation between stage and flow during open-water conditions. The form accommodates three dynamic modes of ice effects: sudden formation-ablation, stable ice conditions, and final elimination. The filter was applied to historical data from two long-term streamflow-gaging stations. They were stable and parameters converged for both stations, producing estimates that were highly correlated with and linearly related to published streamflow values in a log-transformed metric. At St. J ohn River at Dickey, Maine, logarithms of projected streamflow values were within $8 \%$ of the logarithms of published values $87.2 \%$ of the time and within $15 \%$ of published values $96.6 \%$ of the time during periods of ice effects. At Platte River at North Bend, Nebraska, logarithms of projected streamflow values were within $8 \%$ of the logarithms of published daily values $90.7 \%$ of the time and within $15 \%, 97.7 \%$ of the time during ice-affected conditions. This extended Kalman filter allows estimation of ice-affected streamflow at other gaging stations by adjusting filter parameters to site-specific conditions.

Cover: Ice jam in 1991 at St. J ohn River at Dickey, Maine, gage.

How to get copies of CRREL technical publications:

Department of Defense personnel and contractors may order reports through the Defense Technical Information Center:

DTIC-BR SUITE 0944

8725 J OHN J KINGMAN RD

FT BELVOIR VA 22060-6218

Telephone 18002253842

E-mail help@dtic.mil

msorders@dtic.mil

WWW http://www.dtic.dla.mil/

All others may order reports through the National Technical Information Service:

NTIS

5285 PORT ROYAL RD

SPRINGFIELD VA 22161

Telephone 17034874650

E-mail $\quad \begin{aligned} & 17034874639 \text { (TDD for } \\ & \text { orders@ntis.fedworld.gov }\end{aligned}$

WWW http://www.fedworld.gov/ntis/ntishome.html

A complete list of all CRREL technical publications is available from

USACRREL (CECRL-LP)

72 LYME RD

HANOVER NH 03755-1290

Telephone 16036464338

E-mail techpubs@crrel.usace.army.mil

For information on all aspects of the Cold Regions Research and Engineering Laboratory, visit our World Wide Web site: http://www.crrel.usace.army.mil 


\section{CRREL Report 97-8}

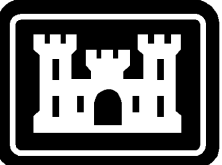

US Army Corps of Engineers

Cold Regions Research \& Engineering Laboratory

\section{Projecting Ice-Affected Streamflow by Extended Kalman Filtering}

David J. Holtschlag, Charles T. Parker, and Mohinder S. Grewal 


\section{PREFACE}

This report was prepared by David J. Holtschlag, Hydrologist, Charles T. Parker, Computer Assistant, U.S. Geological Survey, Water Resources Division, Lansing, Michigan, and Dr. Mohinder S. Grewal, Professor of Electrical Engineering, California State University at Fullerton.

Technical reviewers were Steven F. Daly (CRREL), Glenn B. Engle (USGS), and Joseph P. Nielsen (USGS).

Kathleen D. White, CRREL, assisted in selecting sites for analysis. David Flynn, California State University at Fullerton, provided an algorithm that was used as the basis for implementation in this analysis. Glenn B. Engel, Nebraska District, USGS, and Joseph P. Nielsen, Maine District, USGS, provided hydrological and climatological data.

The contents of this report are not to be used for advertising or promotional purposes. Citation of brand names does not constitute an official endorsement or approval of the use of such commercial products. 


\section{CONTENTS}

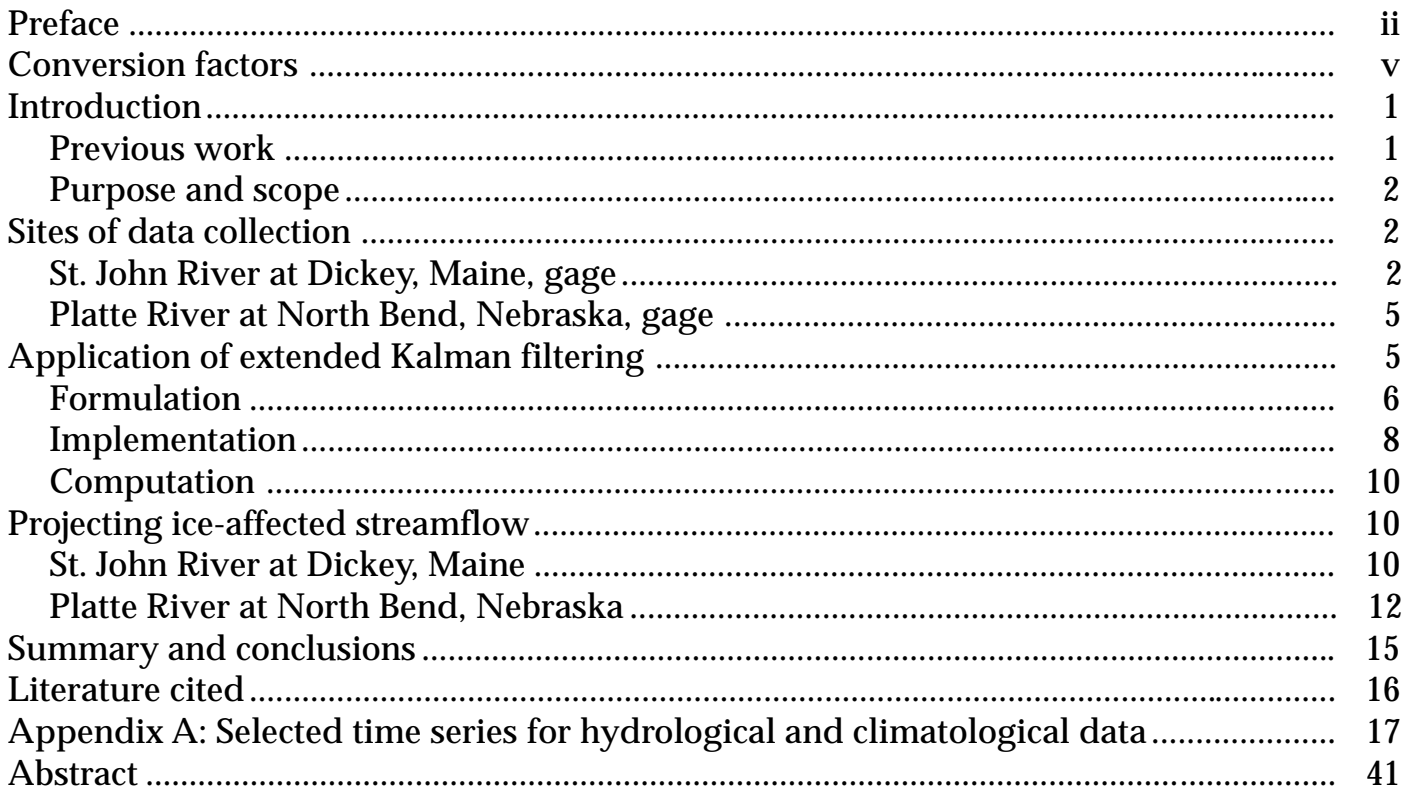

\section{ILLUSTRATIONS}

Figure

1. Selected streamflow-gaging and climatological stations near the St. John River, Dickey, Maine

2. Distribution of streamflow ratios inferred from selected ice-affected periods at St. John River at Dickey, Maine, gage from 1971 through 1993

3. Distribution of average daily air temperatures at Fort Kent, Maine, during selected ice-affected periods at St. John River at Dickey, Maine, gage from 1971 through 1993

4. Selected streamflow-gaging and climatic stations near the Platte River at North Bend, Nebraska

5. Distribution of streamflow ratios inferred from selected ice-affected periods at Platte River at North Bend, Nebraska, gage from 1965 through 1994.

6. Distribution of average daily air temperatures at Fremont, Nebraska, during selected ice-affected periods at Platte River at North Bend, Nebraska, gage from 1965 through 1994 1 1 2 2 2 5 5 6 8 41

Relationship between published streamflow and temporal updates of streamflow on selected days of direct measurement at St. John River at Dickey, Maine, gage from 1971 through 1993

8. Relationship between published and projected streamflow during selected iceaffected periods at St. John River at Dickey, Maine, gage from 1971 through 1993 
Figure

9. Distribution of discrepancies between logarithms of published and projected streamflow during selected ice-affected periods at St. John River at Dickey, Maine, gage from 1971 through 1993

10. Relationship between published streamflow and temporal updates of streamflow on selected days of direct measurement at Platte River at North Bend, Nebraska, gage from 1965 through 1994

11. Relationship between published and projected streamflow during selected iceaffected periods at Platte River at North Bend, Nebraska, gage from 1965 through 1994 .

12. Distribution of discrepancies between logarithms of published and projected streamflow during selected ice-affected periods at Platte River at North Bend, Nebraska, gage from 1965 through 1994

\section{TABLES}

Table

1. Threshold and filter parameters for the extended Kalman filter for the St. John

River at Dickey, Maine

2. Threshold and filter parameters for the extended Kalman filter for the Platte

River at North Bend, Nebraska 


\section{CONVERSION FACTORS: NON-SI UNITS TO SI UNITS OF MEASUREMENT}

These conversion factors include all the significant digits given in the conversion tables in the ASTM Metric Practice Guide (E 380-93), which has been approved for use by the Department of Defense. Converted values should be rounded to have the same precision as the original (see E 380-93).

\begin{tabular}{lll}
\multicolumn{1}{c}{ Multiply } & \multicolumn{1}{c}{ By } & \multicolumn{1}{c}{ To obtain } \\
\hline foot & 0.3048 & meter \\
mile & 1609.347 & meter \\
square mile & 2.590 & square kilometer \\
cubic foot per second & 0.02832 & cubic meter per second \\
degrees Celsius & $t_{{ }^{\circ} \mathrm{C}}=\left(t_{{ }^{\circ} \mathrm{F}}-32\right) / 1.8$ & degrees Fahrenheit \\
\hline
\end{tabular}




\title{
Projecting Ice-Affected Streamflow by Extended Kalman Filtering
}

\author{
DAVID J. HOLTSCHLAG, CHARLES T. PARKER, \\ AND MOHINDER S. GREWAL
}

\section{INTRODUCTION}

The U.S. Army Corps of Engineers is responsible for mitigating flood damage and maintaining navigable conditions in rivers throughout the U.S. Decisions affecting the day-to-day operation of Corps dams are based on real-time streamflow data obtained by telemetry from streamflow-gaging stations typically operated by the U.S. Geological Survey (USGS). Ice effects-variable blockage of the channel by ice and increased flow resistance-reduce the accuracy of real-time streamflow data. To improve the controllability of flow during ice-affected periods, CRREL supported this effort to improve real-time estimates of ice-affected streamflow.

USGS operates a network of more than 7200 continuous-record streamflow-gaging stations nationwide (Condes de la Torre 1994). Direct measurements of flow and stage (water-surface elevation in the waterway) are routinely obtained about every 6 weeks. The average relationship between stage and flow during open-water (no ice cover) conditions-the stage-streamflow rating-monotonically increases. The flow indicated by the rating for a particular stage is the apparent streamflow. Deviations in the average relationship between stage and streamflow, which are interpreted from individual direct measurements of them, are described by shifts in the rating. Together with hourly or more frequent measurements of stage, the rating and its shifts are used to compute streamflow records for annual publication, following a comprehensive analysis of streams in a network of gaging stations.

During open-water conditions, uncertainty associated with shifts in the rating usually is small, and doesn't much affect dam operations. Thus, real-time estimates of flow, traditionally determined directly from the rating and in some cases on the basis of a shift in the rating defined from the most recent direct measurement, provide sufficient accuracy. However, during ice-affected periods, the accuracy of real-time streamflow estimates is compromised by rapidly varying ice-backwater conditions and large time-varying shifts. In these conditions, the ratio of the true to the apparent streamflow, called the streamflow ratio, can vary from 1 during open-water conditions to a value near 0 . These shifts create enough uncertainty in traditional real-time flow estimates that dam operations can be hindered.

\section{Previous work}

Melcher and Walker (1992) evaluated and compared 17 methods for estimating ice-affected streamflow that have traditionally been or could potentially be used in the nationwide streamflowgaging station network maintained by USGS. The methods were divided into two general categories, subjective and analytical, depending on whether or not judgment was necessary for method application. They identified two subjective methods that were more accurate than other subjective methods analyzed, and approximately as accurate as the best analytical method. Holtschlag (1996) developed a dynamical-systems approach for computing ice-affected streamflow. This approach ranked higher than the 11 analytical methods investigated by Melcher and Walker (1992) on the 
basis of accuracy and feasibility criteria. The difference equation formulation developed by Holtschlag (1996) provided the basis for the filter presented in this report.

\section{Purpose and scope}

This report describes an extended Kalman filter that can be used to project the expected value and the associated uncertainty of ice-affected streamflow. The filter was applied and evaluated on the basis of historical climatological and streamflow data available near the St. John River at Dickey, Maine, and near the Platte River at North Bend, Nebraska. The filter was restricted to forms that could be automated and applied by use of data that have been routinely compiled and that could be readily obtained in real time.

\section{SITES OF DATA COLLECTION}

Two sites for development and initial application of the filter were selected to represent a sample of severe ice-backwater conditions in the U.S. In addition, the selected USGS streamflow gaging stations, St. John River at Dickey, Maine (station 01010500), and Platte River at North Bend, Nebraska (station 06796000), have a long historical record of streamflow data and are located close enough to climatological data collection sites to support filter development and evaluation.

\section{St. John River at Dickey, Maine, gage}

The gage is located in northern Maine, about 160 miles north of Bangor, and about 9 miles southwest of the border with Canada (Fig. 1). It is situated on the south (right) bank of the river, about 500 $\mathrm{ft}$ downstream from the bridge over the St. John River near the end of State Route 161. The drainage area at the gage is $2680 \mathrm{mi}^{2}$.

Daily streamflow data have been compiled at the gaging station since September 1946. Station records through water year* (WY) 1995 show a maximum instantaneous flow of $91,700 \mathrm{ft}^{3} / \mathrm{s}$ on 29 April 1979, a minimum daily mean flow of $135 \mathrm{ft}^{3} / \mathrm{s}$ on 15 September 1948, and an average of $4771 \mathrm{ft}^{3} / \mathrm{s}$. The stage-streamflow relation is usually affected by ice from early December through midApril. Minimum and maximum air temperature data are recorded at the Fort Kent climatological station, which is located about 25 miles eastnortheast of the gaging station (Fig. 1). Climatological data for the Fort Kent station are published by the National Oceanic and Atmospheric Administration under station number 2878 .

In this report, 17 years of daily

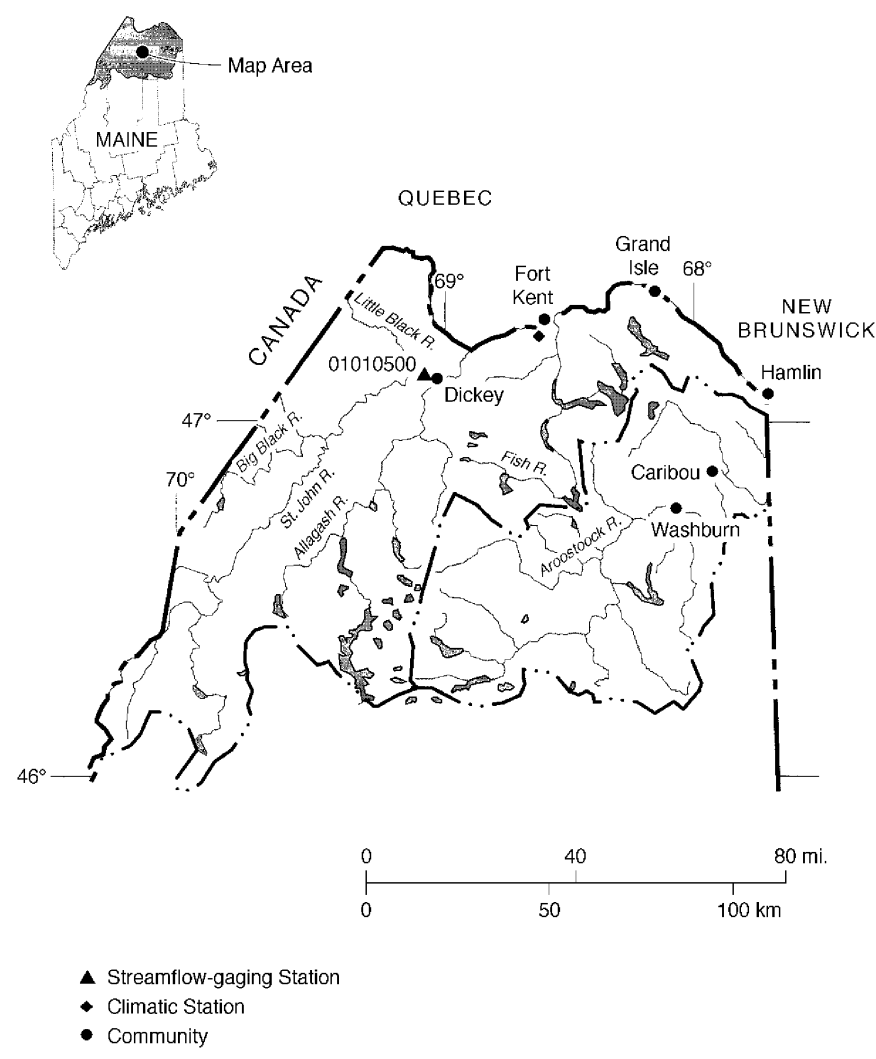

Figure 1. Selected streamflow-gaging and climatological stations near the St. John River at Dickey, Maine.

* A water year is the 12 months from 1 October to 30 September of the next year. For example, WY 1990 runs from 1 October 1989 thorough 30 September 1990. 


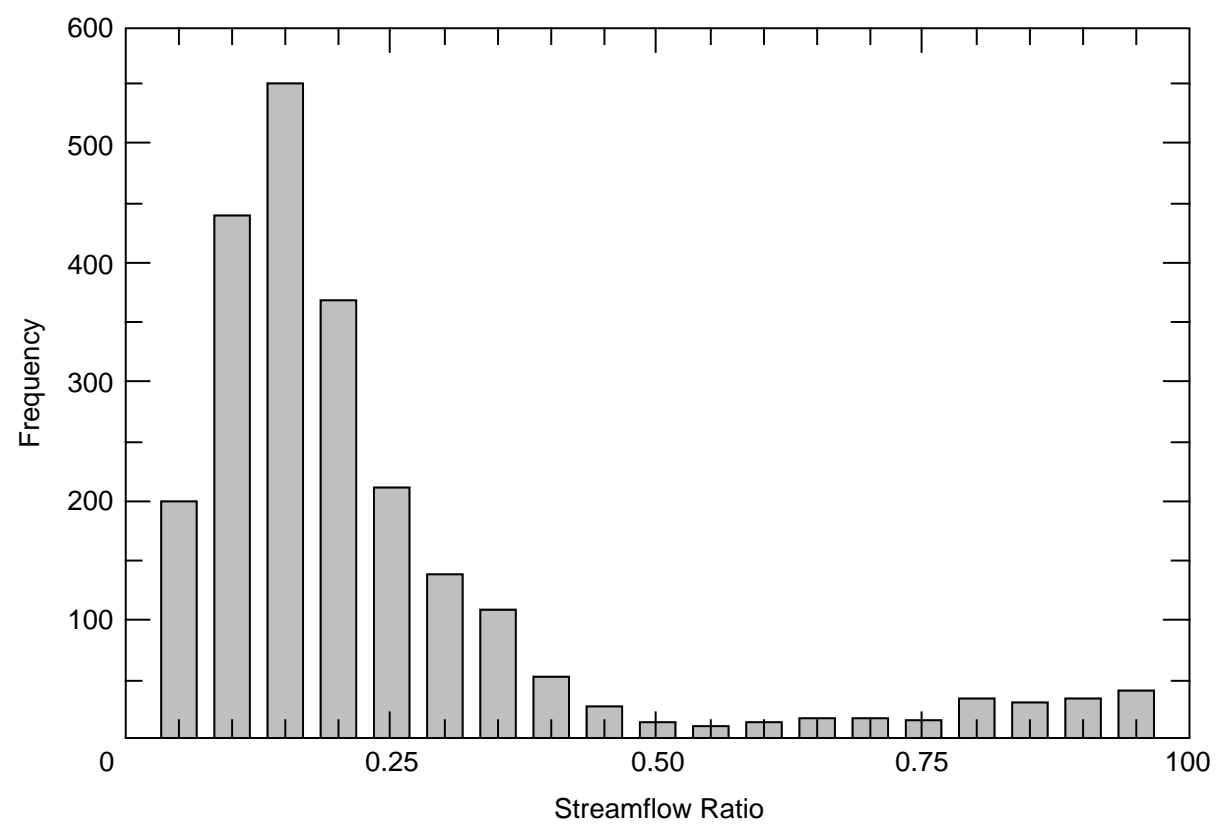

Figure 2. Distribution of streamflow ratios inferred from selected ice-affected periods at St. John River at Dickey, Maine, gage from 1971 through 1993.

streamflow and climatolological data were analyzed. The periods included WY 1971-74, 1978-79, and 1983-93; intervening periods were omitted owing to intervals of missing stage or climatolological data. Within the selected periods, $37.1 \%$ (2303 days) of the daily values were from ice-affected conditions, as shown by streamflow ratios of less than 1 . The distribution of streamflow ratios, inferred by dividing published values by corresponding apparent values, is right skewed, with a mode class of 0.15 (Fig. 2). For the selected periods, the minimum streamflow ratio was 0.014 and the mean of ice-affected streamflow ratios was 0.23 . The corresponding distribution of daily mean air temperature values, computed as the average of the daily maximum and minimum values, on days of ice effects is approximately symmetrically distributed with a mean of $-9.4^{\circ} \mathrm{C}$ (Fig. 3).

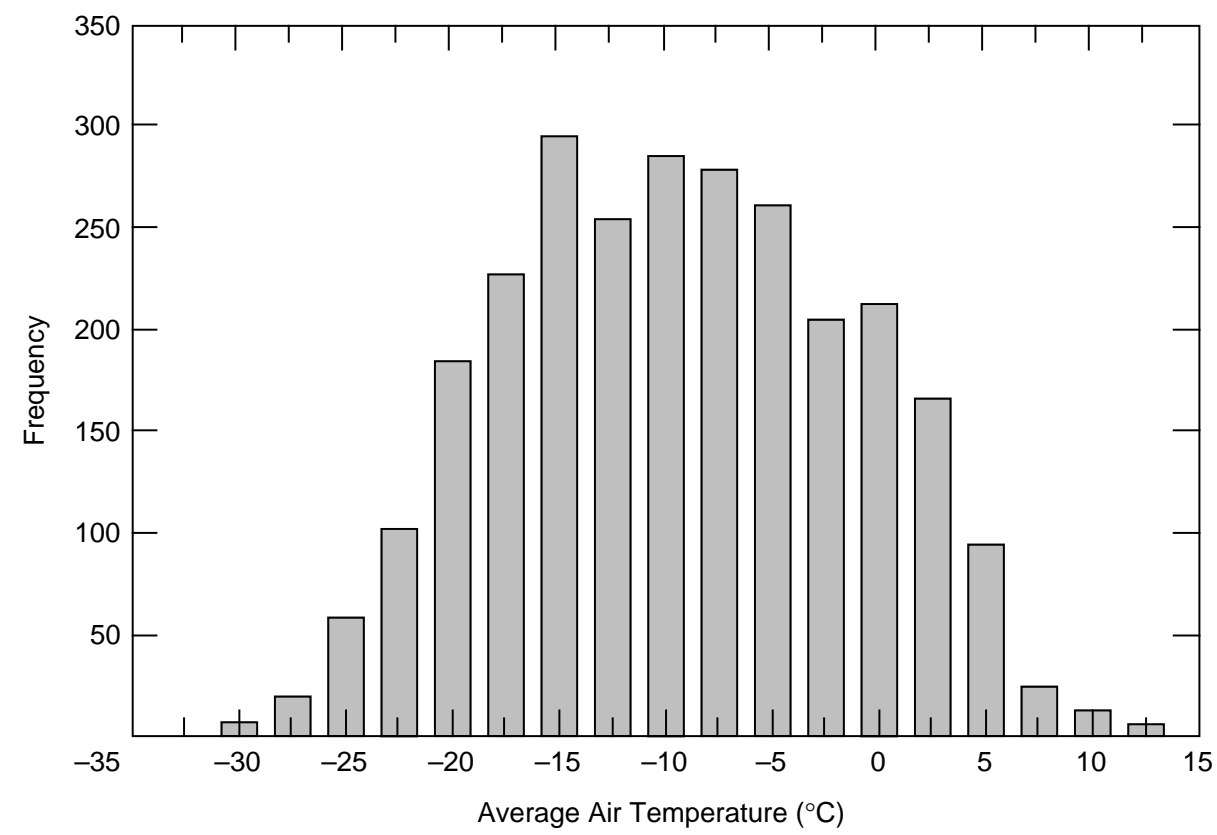

Figure 3. Distribution of average daily air temperatures at Fort Kent, Maine, during selected ice-affected periods at St. John River at Dickey, Maine, gage from 1971 through 1993. 

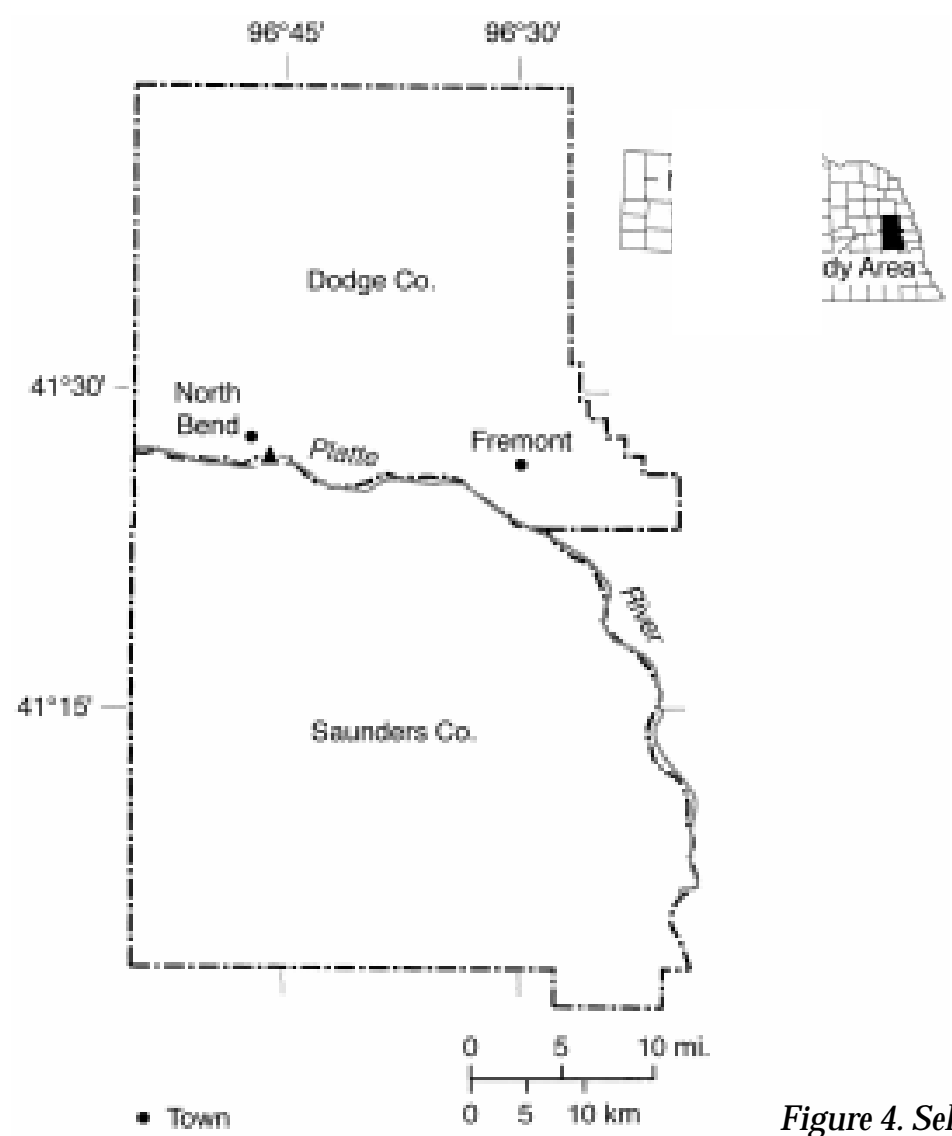

- Gaging Station

Figure 4. Selected streamflow-gaging and climatic stations near the Platte River at North Bend, Nebraska.

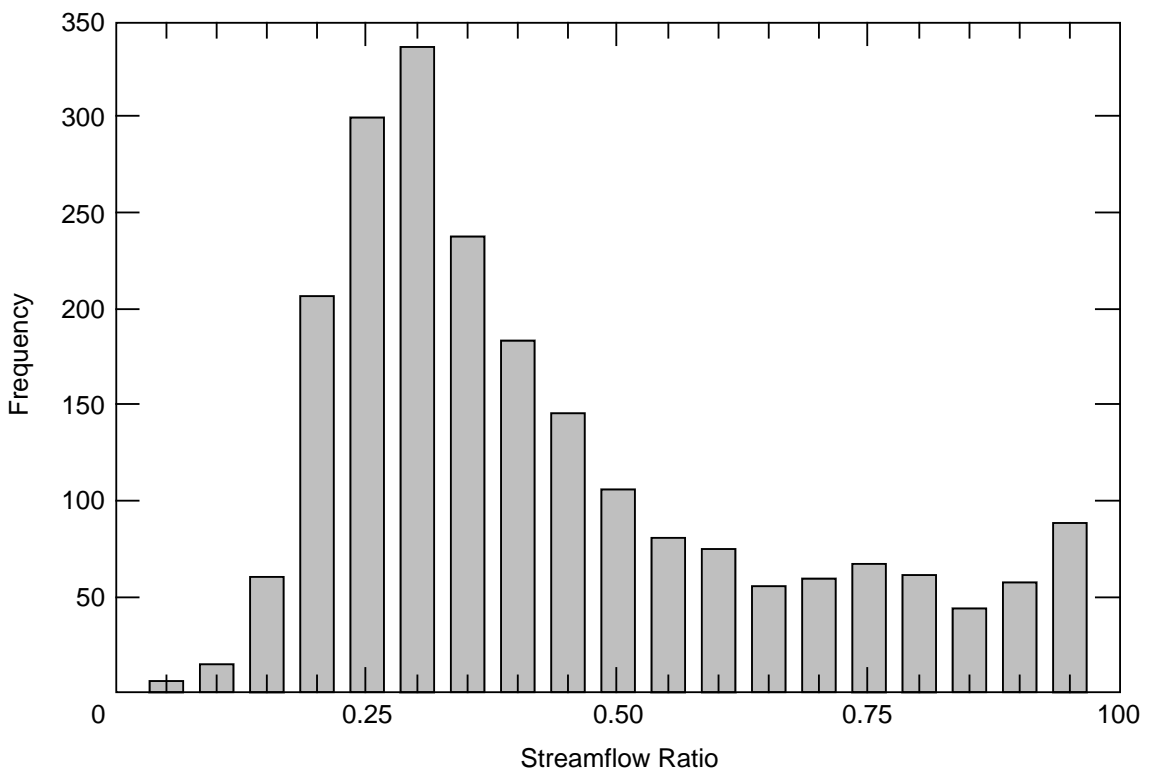

Figure 5. Distribution of streamflow ratios inferred from selected ice-affected periods at Platte River at North Bend, Nebraska, gage from 1965 through 1994. 


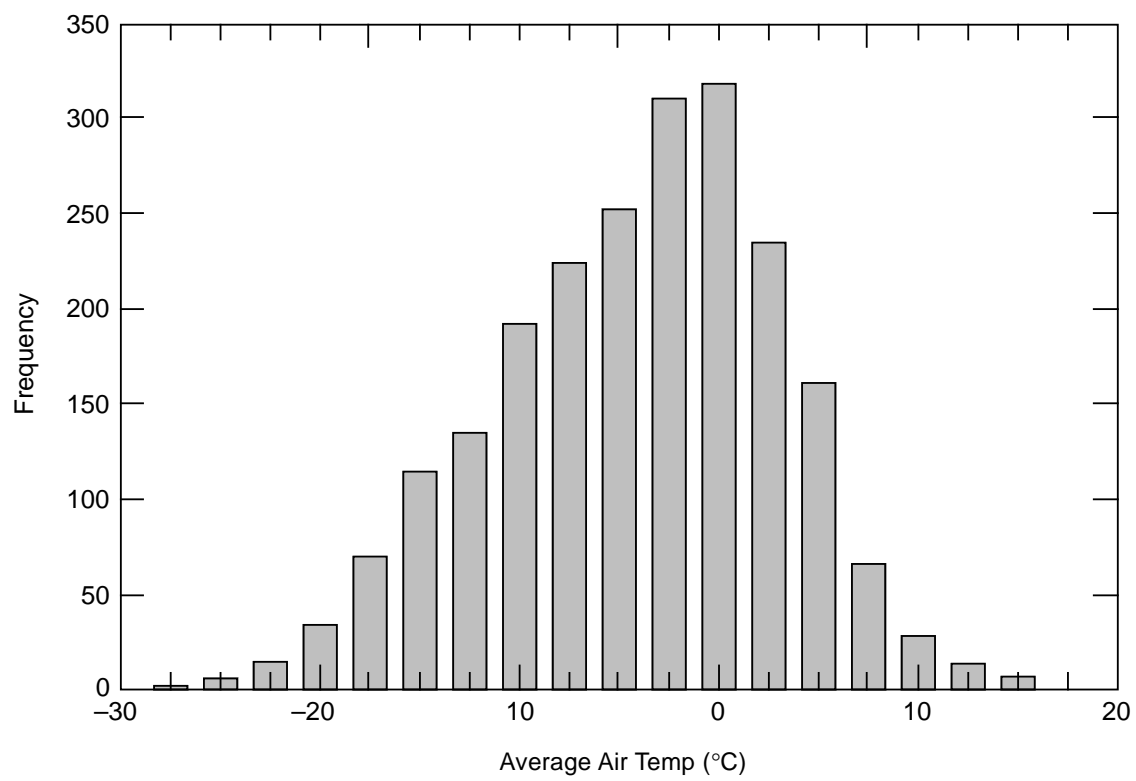

Figure 6. Distribution of average daily air temperatures at Fremont, Nebraska, during selected ice-affected periods at Platte River at North Bend, Nebraska, gage from 1965 through 1994.

\section{Platte River at North Bend, Nebraska, gage}

This gage is located in east-central Nebraska, about 45 miles northwest of Omaha. It (USGS gaging station 06796000) is situated on the north (left) bank of the river, about $80 \mathrm{ft}$ west (upstream) of State Highway 79 (Fig. 4) and about 0.7 miles south of North Bend, Nebraska. The drainage area of the gage is $70,400 \mathrm{mi}^{2}$. Daily streamflow data have been compiled at the gaging station since April 1949. Station records through WY 1995 show a maximum instantaneous flow of 112,000 ft $3 / \mathrm{s}$ on 29 March 1960, a minimum daily mean flow of $36 \mathrm{ft}^{3} / \mathrm{s}$ on 29 July 1974, and an average of 4569 $\mathrm{ft}^{3} / \mathrm{s}$. Air temperature data were obtained from a weather station at Fremont, Nebraska, ${ }^{*}$ which is located about 15 miles east of the gaging station (Fig. 4).

Streamflow at the gaging station is subject to a complete ice cover during the winter. Ice effects are common in November through March; there are severe ice jams at the gage in most years. In this report, 27 years of daily streamflow and climatological data were analyzed: WY 1965-67, 1969-70, 1972-90, and 1992-94. Intervening periods were omitted owing to missing stage or climatological data.

Within the period analyzed, $28.9 \%$ (2179 days) of daily streamflow values were affected by ice, as indicated by a streamflow ratio of less than 1 . The distribution of streamflow ratios during periods of ice effects is skewed to the right, with a mode class of 0.30 (Fig. 5). For the periods of analysis, the minimum streamflow ratio was 0.045 and the mean of ice-affected streamflow ratios was 0.43 . The corresponding distribution of daily mean air temperatures on days of ice effects has a mode class of $0^{\circ} \mathrm{C}$ and a mean of $-4.1^{\circ} \mathrm{C}$ (Fig. 6).

\section{APPLICATION OF EXTENDED KALMAN FILTERING}

Grewal and Andrews (1993), Bar-Shalom and Li (1993), Bozic (1994), Mendel (1995), and Brown and Hwang (1997) all provide detailed information on the mathematical development and general application of Kalman filtering. A Kalman filter estimates the state of a dynamic system, given measurements that are related to the state. The extended form of the Kalman filter was selected

* Personal communication with Mat Werner, Climate Resources Specialist, High Plains Climate Center, University of Nebraska-Lincoln, 1996. 
because the state vector was formulated to include both a signal element (the streamflow ratio) and unknown parameters. In addition to the unknown parameters in the state vector, five threshold parameters were estimated externally to the extended Kalman filter.

A discrete-time formulation was used for consistency with the availability of hydrological and climatological data and for filter simplicity. In this report, the length of the discrete time step was 1 day, a length that facilitated analysis of extensive historical periods of record.

A discrete-time extended Kalman filter was developed to account for the effects of ice on streamflow. The filter consists of two models, a nonlinear process model and a linear measurement model. The general form of the nonlinear process model is

$$
\mathbf{x}(k)=f[\mathbf{x}(k-1), k-1]+\mathbf{w}(k-1)
$$

where $\mathbf{x}(k)=$ state vector. In this report, the state vector is partitioned into two components. The first is the streamflow ratio and is called the state signal element. The second is the state parameter vector. The total number of elements in the state vector is the dimension of the state space.

$f[\mathbf{x}(k-1), k-1]=$ nonlinear function of the state at the previous time step plus other information on auxiliary variables available at time $k-1$.

$\mathbf{w}(k-1)=$ value from a random sequence representing process noise ${ }^{*}$ at time $k-1$. The sequence $\mathbf{w}$ is assumed to be independent and normally distributed, with a mean of zero and a diagonal covariance structure $Q(k-1)$ commonly written $\mathbf{w} \sim N[0, Q(k-1)]$. In this application, only the variance of $\mathbf{x}_{1}(k)$ was assumed be nonzero; no process noise was associated with the state parameters.

The time-varying linear measurement model is of the form

$$
z(k)=H(k) \mathbf{x}(k)+v(k)
$$

where $z(k)=$ streamflow at time $k$.

$H(k)=$ time-varying measurement sensitivity matrix that is represented by the vector $[h(k) 00]$, where $h(k)$ is the apparent streamflow.

$v(k)=$ value from a random sequence representing measurement noise at time $k$. The sequence $v$ is assumed to be independent and normally distributed, with a mean of zero and variance of $R(k)$. The subset of days indexed by $k$ on which direct measurements of streamflow were obtained is denoted as $k^{\prime}$. For developing a projection, the variance $R\left(k^{\prime}\right)$ was assumed to be proportional to the published streamflow on days of direct measurement. In open-water conditions, the standard error was assumed to be $2.5 \%$ of the published values; during ice-affected conditions, the standard error was assumed to be $8.0 \%$ of the published streamflow. On days without direct measurement, published flow data were not used to update the estimate of the streamflow ratio.

\section{Formulation}

Based upon analysis of historical streamflow characterizations developed by traditional methods for estimating ice-affected flow, the dynamics of ice effects were classified into three modes. Mode 1 dynamics are generated by the sudden formation-ablation of ice, as indicated by abrupt changes in apparent streamflow. Mode 2 dynamics are caused by stable ice conditions and are approximated by a first-order difference equation relating the streamflow ratio to air temperature

\footnotetext{
* In the analysis of dynamic systems, noise is random inputs that cannot be directly measured or controlled.
} 
values. Mode 3 dynamics, finally, come from the eventual elimination of ice effects at higher air temperatures. Each mode corresponds to a unique process model; however, the measurement model was consistent for each mode.

The process model for mode 1 dynamics is an algebraic equation of the form

$$
x_{1}(k)=\frac{h(k-1)}{h(k)} \cdot x_{1}(k-1) .
$$

Mode 1 dynamics were applied for either of two conditions:

-If the 1 day change in apparent streamflow increased by more than $q \_d l$ percent and the average air temperature was less then $t \_l o$.

-If the one day change in apparent streamflow decreased by more than $q_{-} d l$ percent when the streamflow ratio was less than 1.

Because of the lack of derivative information in eq $3, q_{-} d l$ and $t \_l o$ were included among five threshold parameters estimated outside the extended Kalman filter. Thus, for mode 1 dynamics, the state vector only included the streamflow ratio and the corresponding dimension of the state space was 1.

The process model for mode 2 dynamics was a first-order difference equation, driven by air temperatures $u$, that was similar to one developed and implemented in a previous investigation (Holtschlag 1996). The process model for mode 2 dynamics is of the form

$$
x_{1}(k)=x_{2}(k-1)+x_{3}\left[x_{1}(k-1)-x_{2}(k-1)\right]+x_{4}(k-1)\left[\tilde{u}(k-1)-x_{5}(k-1)\right]
$$

which says that at times of ice effects and constant air temperature $x_{5}$, the streamflow ratio $\left(x_{1}\right)$ is in equilibrium about a nominal value $x_{2}$. Changes from the equilibrium value are described by a difference equation that includes an autoregressive component with parameter $x_{3}$ and a forcing function term driven by daily air temperature values. Air temperatures that vary from a nominal value of $x_{5}$ change the streamflow ratio from its nominal value of $x_{2}$ at a rate of $x_{4}$. This form of a difference equation is nonlinear in parameters because both rate parameters $\left(x_{3}\right.$ and $\left.x_{4}\right)$ and offset parameters $\left(x_{2}\right.$ and $\left.x_{5}\right)$ are estimated simultaneously.

Prior information on the distribution of streamflow ratios during periods of ice effects was used in hope of facilitating the solution of this inherently difficult estimation problem. Air temperature values $\tilde{u}$ indicate an exponentially weighted average of temperatures from the 3 previous days. An exponential weighting factor $t_{-} w t$, used in computing $\tilde{u}$, was included among threshold parameters, because it did not occur explicitly in eq 4 . The dimension of the state space for mode 2 dynamics is 5 .

The process model for mode 3 dynamics is an algebraic equation of the form

$$
x_{1}(k)=x_{1}(k-1)+\frac{\tilde{u}(k-1)-t_{-} h i}{t_{-} o u-t_{-} h i}\left[1-x_{1}(k-1)\right] .
$$

Mode 3 dynamics are applied when the exponentially weighted air temperature value exceeds $t$ h $h$. Then, the streamflow ratio increases from its value at time $k-1$ to a value of 1 when the exponentially weighted air temperatures equal $t_{-} \mathrm{ou}$. Because $t \_h i$ and $t \_o u$ occur explicitly in the process model, they could be included as parameters in the state vector. However, for simplicity in this analysis, they were included among threshold parameters estimated outside of the extended Kalman filter. As in the case of mode 1 dynamics, the dimension of the state space for mode 3 dynamics was treated as 1 . Estimates of streamflow ratio for all dynamic modes were constrained to the interval between the minimum ratio of published to apparent streamflow determined from historical record and 1.

The process models for the three dynamic modes were developed so that the first (only) element in the state vector was the signal element (the estimated streamflow ratio). For this application, 
changes in mode only affected the signal element. In contrast, the state parameter vector was treated as if mode 2 dynamics were always taking place. Although this convention can create uncertainty in the state parameter vector, the effect is lessened because updates affecting the parameter vector are only computed for days of direct streamflow measurement. Direct measurements are not possible during mode 1 or 3 dynamics because of unsafe measuring conditions.

\section{Implementation}

The extended Kalman filter was implemented by recursively computing daily updates to the state vector $\mathbf{x}$ and the state error covariance matrix $P$, given an initial estimate of the state vector $\mathbf{x}_{0}$ and $P_{0}$. The update has two steps: a temporal update and an observational update. The temporal update is computed at each time step; the observational update is computed only on days of direct measurement. The magnitude of $P$ increases with temporal updates and decreases with observational updates. Bootstrap estimates of $\mathbf{x}_{0}$ and $P_{0}$ were computed by iteratively replacing $\mathbf{x}_{0}^{(j+1)}$ with $\mathbf{x}_{\mathrm{f}}^{(j)}$ until $\mathbf{x}_{\mathrm{f}}^{(j+1)} \cong \mathbf{x}_{\mathrm{f}}^{(j)}$, where $\mathbf{x}_{0}$ and $\mathbf{x}_{\mathbf{f}}$ are the initial and final values for the state vector for the $j$ or $j+1$ iteration of the extended Kalman filter, respectively.

\section{Temporal updates}

The temporal update represents the best linear estimate of the state at time $k$ without consideration of available observations at time $k$, but only information available at $k-1$. The notational form used for the general state equation is

$$
\mathbf{x}^{(-)}(k)=f\left\{\mathbf{x}^{(+)}[(k-1), k-1]\right\} .
$$

For mode 1 dynamics, the signal element is replaced by

$$
x_{1}^{(-)}(k)=\frac{h(k-1)}{h(k)} \cdot x_{1}(k-1) .
$$

In the case of mode 2 dynamics, the temporal update is written

$$
\left[\begin{array}{l}
x_{1}^{(-)}(k) \\
x_{2}^{(-)}(k) \\
x_{3}^{(-)}(k) \\
x_{4}^{(-)}(k) \\
x_{5}^{(-)}(k)
\end{array}\right]=\left[\begin{array}{c}
x_{2}^{(+)}(k-1)+x_{3}^{(+)}\left[x_{1}^{(+)}(k-1)-x_{2}^{(+)}(k-1)\right]+x_{4}^{(+)}(k-1)\left[\tilde{u}(k-1)-x_{5}^{(+)}(k-1)\right] \\
x_{2}^{(+)}(k-1) \\
x_{3}^{(+)}(k-1) \\
x_{4}^{(+)}(k-1) \\
x_{5}^{(+)}(k-1)
\end{array}\right] .
$$

Finally, in the case of mode 3 dynamics, the signal element is computed as

$$
x_{1}^{(-)}(k)=x_{1}^{(+)}(k-1)+\frac{\tilde{u}(k-1)-t_{-} h i}{t_{-} \text {ou }-t_{-} h i}\left[1-x_{1}^{(+)}(k-1)\right]
$$

for specified threshold parameters $t \_h i$ and $t \_o u$.

A temporal update of streamflow is computed by multiplying the apparent streamflow by the estimated streamflow ratio, or, for consistency with the extended Kalman filter notation, by multiplying the time-varying measurement sensitivity matrix $H(k)$ times the temporal update of the state vector as

$$
\hat{z}^{(-)}(k)=H(k) \mathbf{x}^{(-)}(k)=[h(k) 00] \mathbf{x}^{(-)}(k) .
$$

A temporal update of the error covariance matrix is computed as 


$$
P^{(-)}(k)=\Phi^{[1]}(k-1) P^{(+)}(k-1) \Phi^{[1]^{T}}(k-1)+Q(k-1) .
$$

A first order approximation of the state transition matrix is given by

$$
\Phi^{[1]}(k-1) \approx \frac{\partial}{\partial x} f\left[x, k-\left.1\right|_{x=x^{(-)}(k-1)} .\right.
$$

The estimate of the transition matrix used in this analysis is

$$
\Phi^{[1]}(k-1)=\left[\begin{array}{ccccc}
x_{3}^{(-)}(k-1) & 1-x_{3}^{(-)}(k-1) & x_{1}^{(-)}(k-1)-x_{2}^{(-)}(k-1) & \tilde{u}(k-1)-x_{5}^{(-)}(k-1) & x_{4}^{(-)}(k-1) \\
0 & 1 & 0 & 0 & 0 \\
0 & 0 & 1 & 0 & 0 \\
0 & 0 & 0 & 1 & 0 \\
0 & 0 & 0 & 0 & 1
\end{array}\right] .
$$

The value of $Q$ was determined such that

$$
\operatorname{Prob}\left[\hat{z}^{(-)}(k) \pm Z_{\alpha=0.1} P_{1,1}^{(-)}(k)>z(k)\right] \sim 0.9
$$

where $Z_{\alpha=0.1}$ is the standardized normal deviate corresponding to a $90 \%$ probability and equaling 1.64 .

Observational updates

Observational updates were computed for days of direct flow measurement. First, the Kalman gain matrix was computed as

$$
\bar{K}\left(k^{\prime}\right)=P^{(-)}\left(k^{\prime}\right) H^{T}\left(k^{\prime}\right)\left[H\left(k^{\prime}\right) P^{(-)}\left(k^{\prime}\right) H^{T}\left(k^{\prime}\right)+R\left(k^{\prime}\right)\right]^{-1} .
$$

Then the covariance matrix was updated as

$$
P^{(+)}\left(k^{\prime}\right)=\left[I-\bar{K}\left(k^{\prime}\right) H\left(k^{\prime}\right)\right] P^{(-)}\left(k^{\prime}\right)
$$

The state vector update was computed as

$$
\mathbf{x}^{(+)}\left(k^{\prime}\right)=\mathbf{x}^{(-)}\left(k^{\prime}\right)+\bar{K}\left(k^{\prime}\right)\left[z\left(k^{\prime}\right)-\hat{z}^{(-)}\left(k^{\prime}\right)\right] .
$$

And finally the observational update was computed as

$$
\hat{z}^{(+)}(k)=H(k) \mathbf{x}^{(+)}(k)=[h(k) 00] \mathbf{x}^{(+)}(k) .
$$

On days without direct flow measurement, observational updates were set equal to the temporal updates computed for that time step. Thus, projected values computed by use of the extended Kalman filter were equal to the observational updates on days of direct streamflow measurement and were equal to the temporal updates otherwise. No adjustment was included for uncertainty in the apparent streamflow values.

\section{Computation}

Computational procedures were developed and tested in the MATLAB programming environment (The MathWorks, Inc., Natick, Massachusetts) on the basis of algorithms developed by Grewal and Andrews (1993). To provide numerical stability, the temporal update of the error covariance 
matrix was computed by use of the Thornton UD factorization algorithm (Grewal and Andrews 1993, p. 255) rather than by directly using eq 6-13. Similarly, the Bierman observational update algorithm (Grewal and Andrews 1993, p. 245) with corrections provided by D. Flynn* was used rather than directly using eq 15-17. The MATLAB code was converted to code in the C++ programming language (Weiss 1996) for improved portability (a program listing is available from the first author, $\mathrm{DJH})$.

\section{PROJECTING ICE-AFFECTED STREAMFLOW}

Filter estimates generally are at time $k$, based on measurements up to and including time $k$. In contrast, forecast estimates are made at time $k$, based on data up to, but not including, time $k$. In this report, extended Kalman filter estimates of streamflow are projections, forecasts determined on the basis of the temporal updates. However, on days of direct measurement, more accurate filter estimates are computed by use of observational updates.

\section{St. John River at Dickey, Maine}

The extended Kalman filter was initialized to St. John River data by manually adjusting preliminary estimates of threshold parameter values. This minimized the sum of squared errors in the extrapolated streamflow ratio $x_{1}^{(-)}\left(k^{\prime}\right)-x_{1}\left(k^{\prime}\right)$, where $k^{\prime}$ indicates days of direct streamflow measurements. Once satisfactory estimates of the threshold parameters were obtained, they were fixed (Table 1). Then the filter was run repetitively, using the state vector and error covariance matrix computed on the last iteration of the previous run to initialize the subsequent run. The filter was run repeatedly until elements in the state parameter vector were essentially constant. In this process, initial estimates for the state error covariance matrix converged from an initially specified diagonal matrix with nonzero components of [0.5 0.50 .01 10] to the standard errors shown in Table 1.

Final estimates for the state parameters indicate that mode 1 dynamics are highly autoregressive, as shown by the parameter $x_{3}=0.981$, about a streamflow ratio offset of $x_{2}=0.544$. Streamflow ratios increase at a rate $x_{4}=0.000855^{\circ} \mathrm{C}^{-1}$ from the temperature offset $x_{5}=-3.19^{\circ} \mathrm{C}$. Although the value for $x_{2}$

Table 1. Threshold and filter parameters for the extended Kalman filter for the St. John River at Dickey, Maine.

\begin{tabular}{|c|c|c|c|c|}
\hline $\begin{array}{l}\text { Parameter } \\
\text { symbol }\end{array}$ & Parameter description & Estimate & Sensitivity & $\begin{array}{c}\text { Estimated } \\
\text { standard } \\
\text { error }\end{array}$ \\
\hline$t \_h i$ & $\begin{array}{l}\text { High temperature at which ice breakup begins } \\
\text { (in degrees Celsius). }\end{array}$ & 4.50 & -0.0824 & - \\
\hline t_lo & $\begin{array}{l}\text { Low temperature at which sudden increases in apparent } \\
\text { streamflow indicates ice accumulation (in degrees Celsius). }\end{array}$ & -2.25 & 0.00868 & - \\
\hline$t_{-}$ou & $\begin{array}{l}\text { High temperature at which ice breakup is complete } \\
\text { (in degrees Celsius). }\end{array}$ & 10.0 & 0.0427 & - \\
\hline$t \_w t$ & Exponential weighting factor for daily temperatures. & 0.95 & 0.0424 & - \\
\hline$q_{-} d l$ & $\begin{array}{l}\text { Threshold at which changes in apparent daily streamflows } \\
\text { are considered large. }\end{array}$ & 0.35 & -16.1 & - \\
\hline$x_{2}$ & Offset streamflow ratio. & 0.544 & - & 0.0937 \\
\hline$x_{3}$ & Autoregressive parameter for streamflow ratio. & 0.981 & - & 0.000153 \\
\hline$x_{4}$ & $\begin{array}{l}\text { Parameter relating air temperature to changes in } \\
\text { streamflow ratios (in degrees Celsius }{ }^{-1} \text { ). }\end{array}$ & 0.000855 & - & 0.00000459 \\
\hline$x_{5}$ & Offset temperature (in degrees Celsius). & -3.19 & - & 2.08 \\
\hline
\end{tabular}

* Personal communication, California State University at Fullerton, 1996. 
is higher than the mode class of the distribution of empirical streamflow ratios (Fig. 2), it is physically realizable. Similarly, $x_{5}$ is consistent with the distribution of air temperatures during periods of ice effects and the physical conceptualization of the process (Fig. 3). However, analysis of the state error covariance matrix points to a large positive correlation $(>0.99)$ between $x_{2}$ and $x_{5}$ and a large negative correlation $(<-0.93)$ between $x_{3}$ and $x_{4}$. Thus, although the form of the difference equation used to describe mode 1 dynamics resulted in parameters with physically realizable values, the large correlations indicate ambiguity concerning their true values. Because of the high correlations in the state error covariance matrix, there is a potential for reducing the dimension of the state parameter vector without loss of filter accuracy.

Sensitivities for threshold parameters (Table 1) were estimated as the change in the sum of squared errors in the streamflow ratio divided by the change in the corresponding parameter near the selected values. Results of simulations show that filter computations were most sensitive to changes in the $q_{-} d l$ parameter and least sensitive to the $t_{-} l o$ parameter. Formal optimization of the threshold parameters could lead to further improvement in filter performance.

One measure of the projection accuracy of the filter is the relation between temporal updates of streamflow $z_{1}^{(-)}\left(k^{\prime}\right)$ and published daily values $z\left(k^{\prime}\right)$, where $k^{\prime}$ indexes days of direct measurement (Fig. 7). Although this value is modified by observational updates to more precisely project streamflow on days of direct measurement, $z_{1}^{(-)}\left(k^{\prime}\right)$ provides a conservative indication of the filter accuracy. The temporal update is a conservative sign of accuracy because the variance of the projection increases monotonically with time from the previous measurement, and the length of the projection is at maximum just before the observational update. Results for the St. John River show that the correlation between log-transformed values of $z_{1}^{(-)}\left(k^{\prime}\right)$ and $z\left(k^{\prime}\right)$, based on 40 days of ice-affected measurements, is 0.777 and is 0.998 based on 63 days of open-water measurements. Measurements at the St. John River used in this analysis averaged 8.6 weeks apart.

Another measure of filter accuracy is the relationship between published and projected streamflows during periods of ice effects. This relation is linear in the logarithm of transformed values (Fig. 8). Uncertainty occurs in both the published and projected values. Published values during ice effects are subjectively rated "fair" or "poor." A rating of "fair" implies that about $95 \%$ of the daily values are within $15 \%$ of the true value; a "poor" rating means that daily streamflow values have

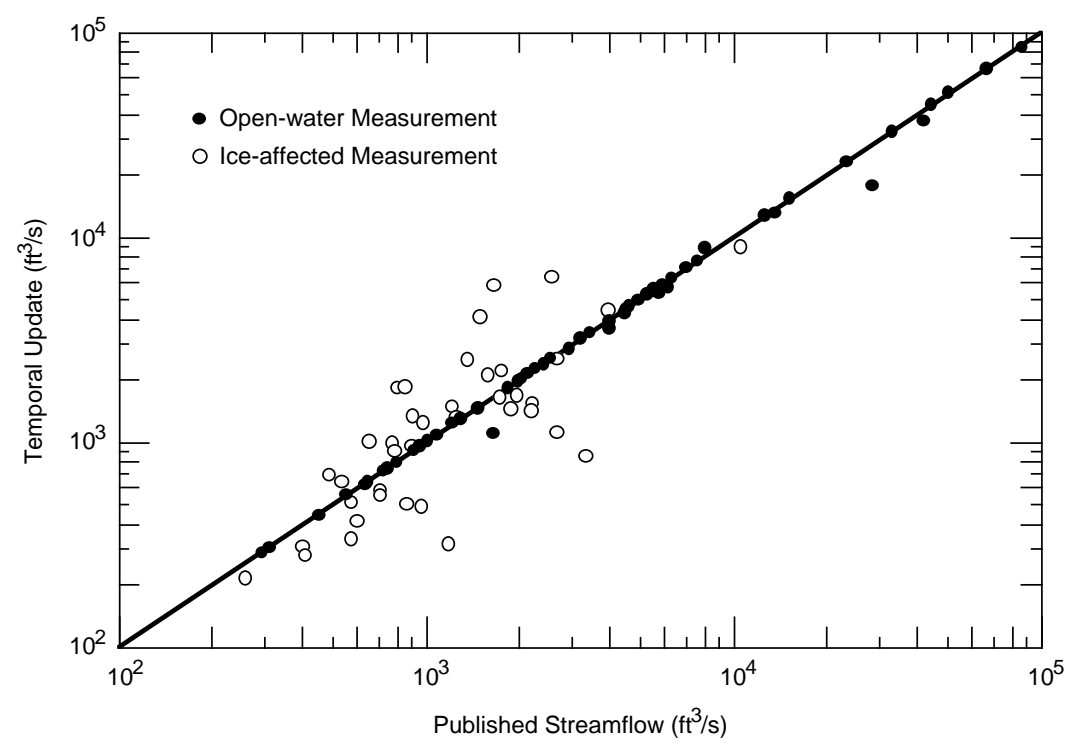

Figure 7. Relationship between published streamflow and temporal updates of streamflow on selected days of direct measurement at St. John River at Dickey, Maine, gage from 1971 through 1993. 
less than "fair" accuracy (Novak 1985, p. 65). Analysis of the distribution of discrepancies (Fig. 9) between published and projected values during periods of ice effects, computed as

$$
e(k)=\frac{\log \left[z^{(+)}(k)\right]-\log [z(k)]}{\log [z(k)]}
$$

indicates that the absolute value of elements in the $e$ sequence are less than $8 \%, 87.2 \%$ of the time and are less than $15 \%, 96.6 \%$ of the time.

Projections of streamflow are shown with other streamflow and climatological data for the selected periods in Appendix A. Upper and lower projections were computed by adjusting the variance of $Q$ to 0.0035 so that the interval formed between the upper and lower projections about the temporal updates at $k^{\prime}$ contained the published values $90 \%$ of the time.

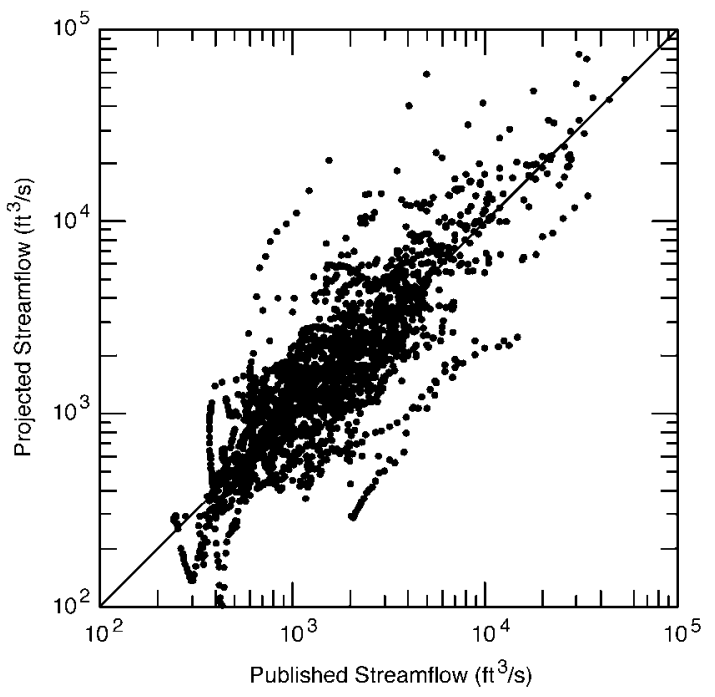

Figure 8. Relationship between published and projected streamflow during selected ice-affected periods at St. John River at Dickey, Maine, gage from 1971 through 1993.

\section{Platte River at North Bend, Nebraska}

The protocol developed for the St. John River was followed when the extended Kalman filter was applied to Platte River data. This was done by manually adjusting preliminary estimates of threshold parameters to minimize the sum of squared errors in the temporal updates of the streamflow ratio for days of direct measurement. Again, once apparently satisfactory estimates of the threshold parameters were obtained, they were fixed (Table 2) and the filter was run until convergence. In this process, initial estimates of the state error covariance matrix converged from an initial diagonal matrix with nonzero elements of [0.5 0.50 .01 10] to a covariance matrix with standard errors shown in Table 2.

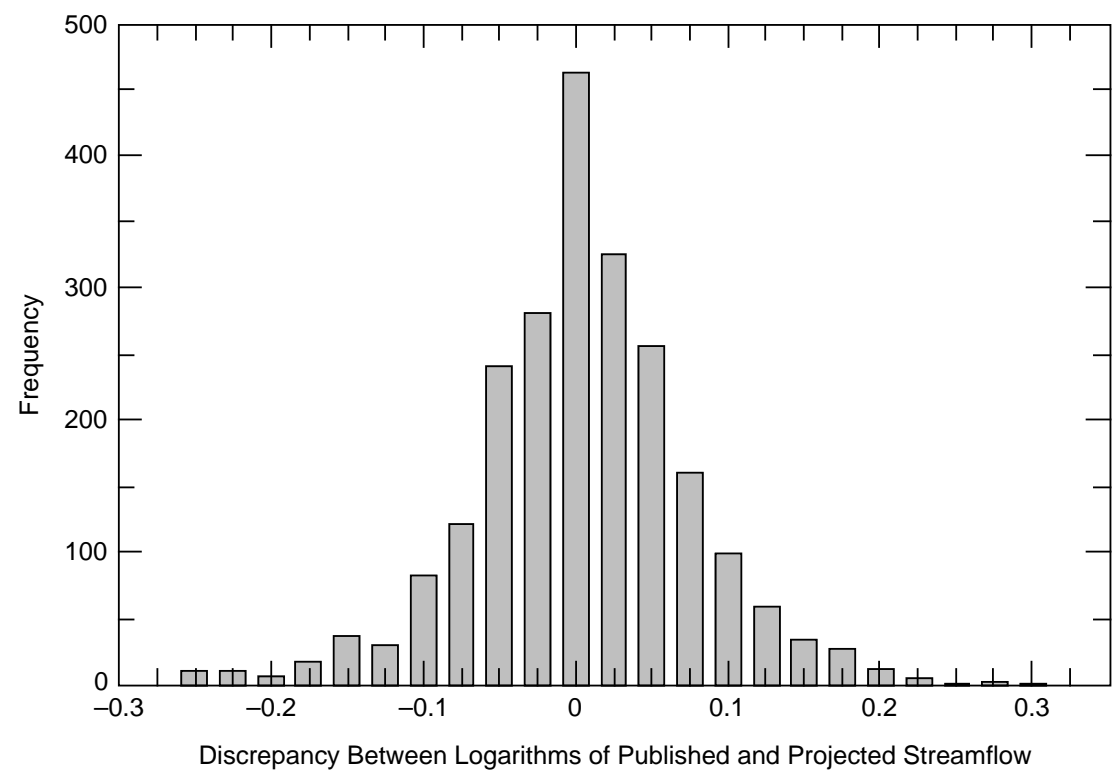

Figure 9. Distribution of discrepancies between logarithms of published and projected streamflow during selected ice-affected periods at St. John River at Dickey, Maine, gage from 1971 through 1993 (logarithms are in base 10). 
Table 2. Threshold and filter parameters for the extended Kalman filter for the Platte River at North Bend, Nebraska.

\begin{tabular}{|c|c|c|c|c|}
\hline $\begin{array}{l}\text { Parameter } \\
\text { symbol }\end{array}$ & Parameter description & Estimate & Sensitivity & $\begin{array}{c}\text { Estimated } \\
\text { standard } \\
\text { error }\end{array}$ \\
\hline \multirow[t]{2}{*}{$t h i$} & High temperature at which ice breakup begins (in degrees & & & \\
\hline & Celsius). & 4.50 & -0.331 & - \\
\hline t_lo & $\begin{array}{l}\text { Low temperature at which sudden increases in apparent } \\
\text { streamflow indicates ice accumulation (in degrees Celsius). }\end{array}$ & -2.25 & -0.141 & - \\
\hline t_ou & $\begin{array}{l}\text { High temperature at which ice breakup is complete (in } \\
\text { degrees Celsius). }\end{array}$ & 10.0 & -0.206 & - \\
\hline$t \_w t$ & Exponential weighting factor for daily temperatures. & 0.95 & 0.430 & - \\
\hline$q_{-} d l$ & $\begin{array}{l}\text { Threshold at which changes in apparent daily streamflows } \\
\text { are considered large. }\end{array}$ & 0.30 & 10.5 & - \\
\hline$x_{2}$ & Offset streamflow ratio. & -0.0681 & - & 0.0132 \\
\hline$x_{3}$ & Autoregressive parameter for streamflow ratio. & 0.990 & - & 0.000186 \\
\hline$x_{4}$ & $\begin{array}{l}\text { Parameter relating air temperature to changes in streamflow } \\
\text { ratios (in degrees Celsius }{ }^{-1} \text { ). }\end{array}$ & 0.000939 & - & 0.00000372 \\
\hline$x_{5}$ & Offset temperature (in degrees Celsius). & -9.37 & - & 0.169 \\
\hline
\end{tabular}

Results from Platte River data also point out that mode 1 dynamics are highly autoregressive, as indicated by the parameter $x_{3}=0.990$. Streamflow ratios increase at a rate $x_{4}=0.000939^{\circ} \mathrm{C}^{-1}$ about a temperature offset $x_{5}=-9.37^{\circ} \mathrm{C}$, a lower temperature than that estimated for the St. John River. Unfortunately, the estimated streamflow ratio offset of $x_{2}=-0.068$ is not physically realizable. Analysis of the state error covariance matrix shows a maximum positive correlation of 0.81 between $x_{3}$ and $x_{5}$ and a maximum negative correlation of -0.74 between $x_{3}$ and $x_{4}$. The magnitudes of these correlations are not thought to be sufficient to significantly degrade parameter estimates. However, given the small magnitude of the estimated $x_{2}$ value, in future applications it may be possible to eliminate (set to zero) the streamflow ratio offset from the difference equation for mode 1 dynamics. Such an elimination would reduce the dimension of the state space, which would also likely reduce parameter ambiguity caused by high correlations in the state error covariance matrix. Values for the threshold parameters that are less than optimal also possibly explain the discrepancy between the estimated value of $x_{2}$ and the conceptualized value.

Sensitivities for threshold parameters (Table 2) were estimated as the change in the sum of squared errors in the streamflow ratio estimate divided by the change in the corresponding parameter near the selected values. The results of simulations indicate that projections are most sensitive to changes in the $q_{-} d l$ parameter and least sensitive to the $t_{-} l o$ parameter. Again, formal optimization of the threshold parameters could lead to further improvement in filter performance.

The temporal updates of streamflow on days of direct measurements compare closely with published daily mean values (Fig. 10). Results show that the correlation between log-transformed values of $z_{1}^{(-)}\left(k^{\prime}\right)$ and $z\left(k^{\prime}\right)$, based on 87 days of ice-affected measurements, is 0.864 and is 0.997 based on 345 days of open-water measurements. Measurements at the Platte River used in this analysis averaged 3.2 weeks apart.

The relationship between published and projected streamflow values at the Platte River during periods of ice effects is linear and unbiased in the logarithms of streamflow (Fig. 11). The distribution of discrepancies between published and projected values (Fig. 12) during periods of ice effects were analyzed by use of eq 18; the absolute value of elements in the $e$ sequence are less than $8 \%$, $90.7 \%$ of the time, and are less than $15 \%, 97.7 \%$ of the time.

Projected streamflows are shown with other flow and climatological data for the selected periods in Appendix A. Upper and lower projections were computed by adjusting the variance of $Q$ to 


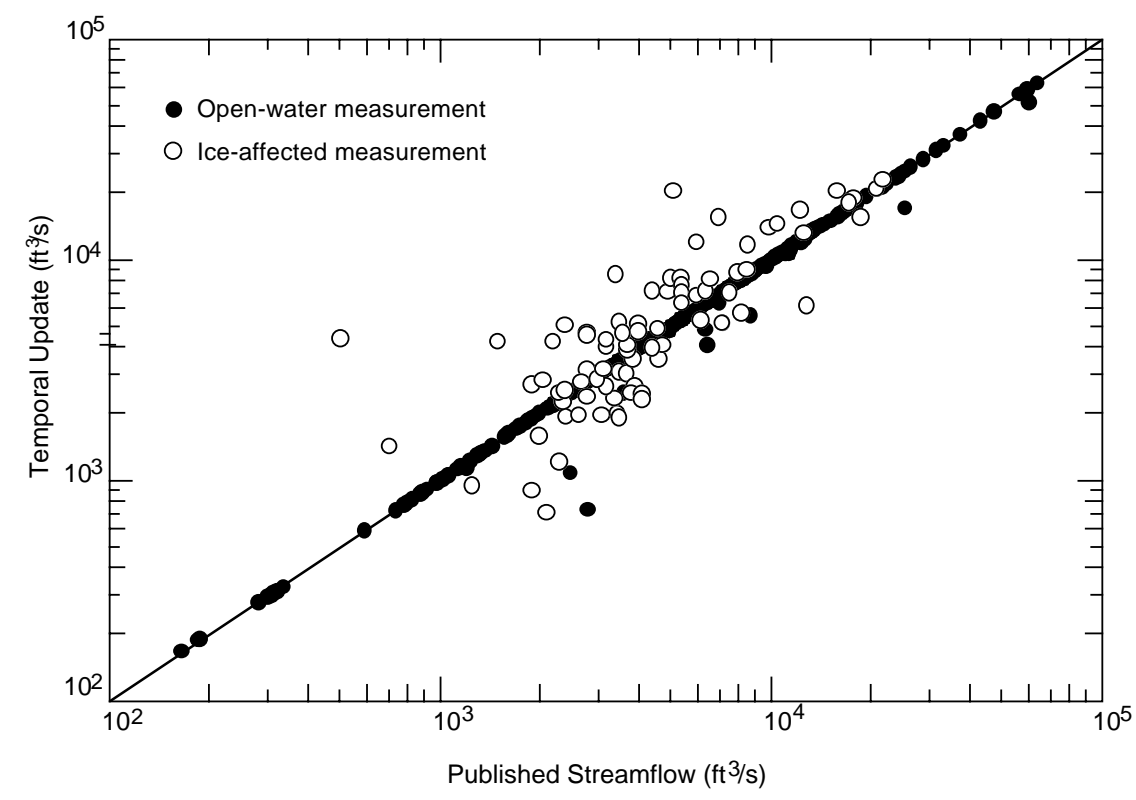

Figure 10. Relationship between published streamflow and temporal updates of streamflow on selected days of direct measurement at Platte River at North Bend, Nebraska, gage from 1965 through 1994.

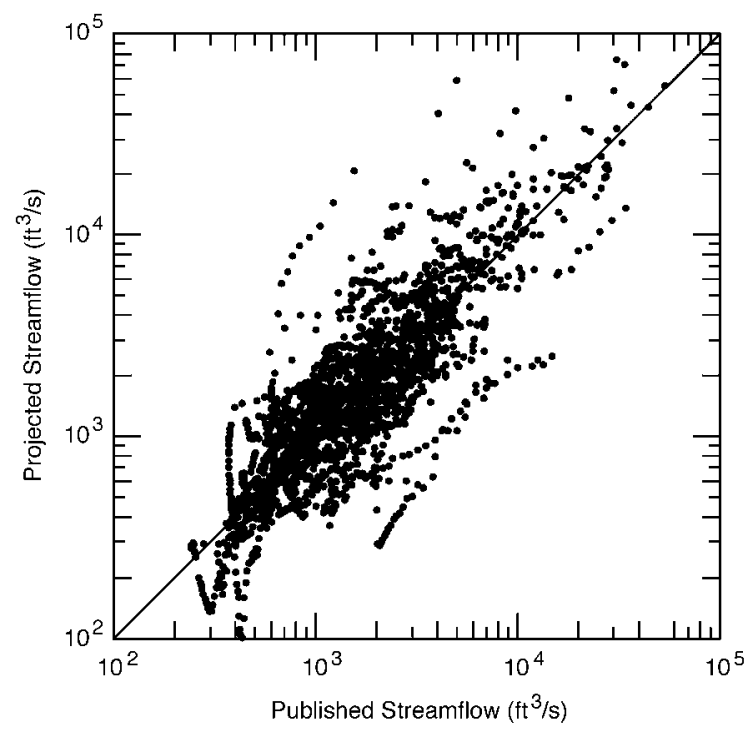

Figure 11. Relationship between published and projected streamflow during selected ice-affected periods at Platte River at North Bend, Nebraska, gage from 1965 through 1994.

0.0039 so that the interval formed by the upper and lower projection about the temporal update at $k^{\prime}$ included the published values $90 \%$ of the time.

\section{SUMMARY AND CONCLUSIONS}

Ice-affected streamflow describes the effects of channel ice on the relationship between stream stage (water-surface elevation) and flow. Because an ice cover physically blocks the channel and increases flow resistance, these effects result in lower flows than would be expected from corre- 


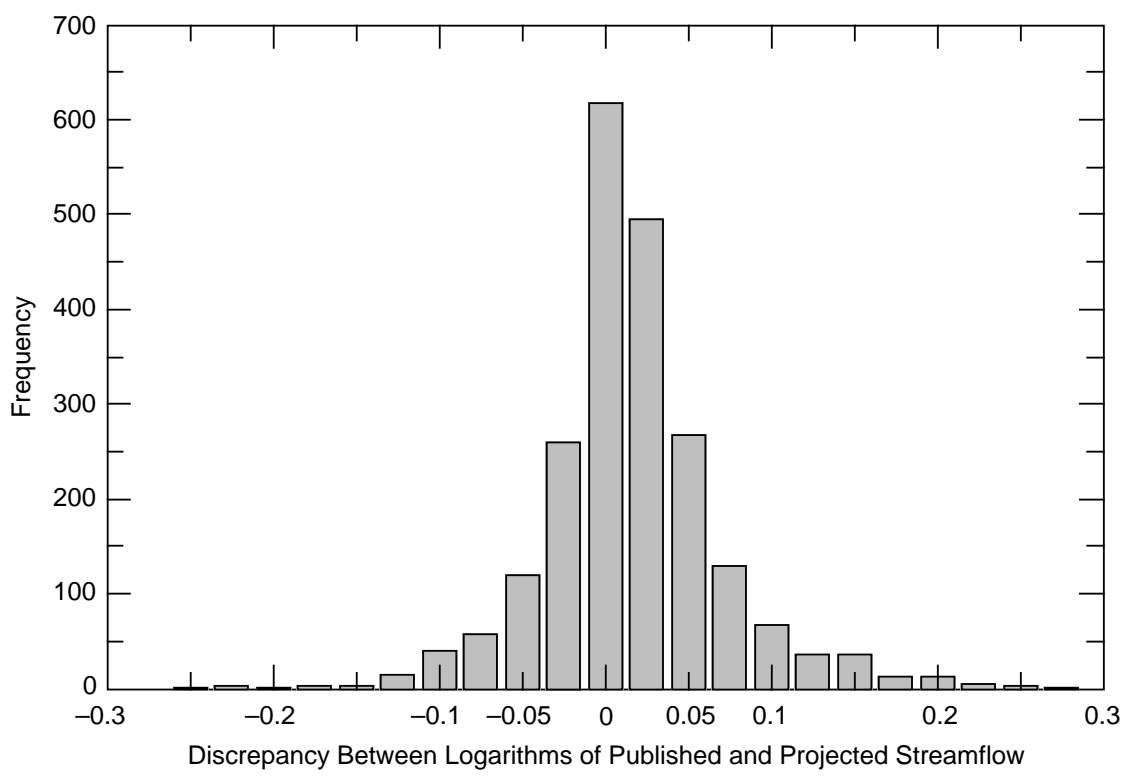

Figure 12. Distribution of discrepancies between logarithms of published and projected streamflow during selected ice-affected periods at Platte River at North Bend, Nebraska, gage from 1965 through 1994.

sponding stages during open-water conditions. In addition, ice effects create uncertainty in realtime streamflow estimates that are needed to help control floods and facilitate navigation.

Three dynamic modes of ice effects were identified on the basis of historical interpretations of ice-affected streamflow records. In the first mode come rapid changes in ice effects, associated with ice formation and ablation, indicated by abrupt changes in apparent streamflow. In the second mode, existing ice effects change with changes in air temperature. In the third mode, ice effects are eliminated with higher air temperatures. Equations for these dynamic modes were developed within a discrete-time extended Kalman filter to project daily values and uncertainties of iceaffected streamflow.

The filter consists of two models: a nonlinear process model and a time-varying linear measurement model. For the dominant mode 2 dynamics, the process model computes the ratio of actual to apparent flow (streamflow ratio) by use of a first-order difference equation driven by daily airtemperature values and four filter parameters. During periods of mode 1 or mode 3 dynamics, the difference equation is replaced by an algebraic expression to estimate the streamflow ratio by use of five threshold parameters.

The measurement model projects a daily mean streamflow on the basis of the estimated streamflow ratio and the apparent streamflow. On days of direct measurement, the projection is computed and the covariance matrix is updated to account for this information. The utility of the filter was evaluated by applying it to historical data from two long-term stream-gaging stations.

The filters developed for stream-gaging stations on the St. John River at Dickey, Maine, and the Platte River at North Bend, Nebraska, were stable, and parameters converged for both stations, allowing projections of ice-affected streamflows. Results for the gaging station at the St. John River indicate that, during periods of ice effects, logarithms of projected streamflow values were within $8 \%$ of the logarithms of published values $87.2 \%$ of the time and within $15 \%, 96.6 \%$ of the time. Results for the gaging station at the Platte River indicate that logarithms of projected streamflow values were within $8 \%$ of the logarithms of published daily values $90.7 \%$ of the time and within $15 \%, 97.7 \%$ of the time. The correlations between temporal updates and published values of streamflow on days of direct measurement are 0.777 and 0.998 , for data from the St. John River, and 0.864 
and 0.997 for data from the Platte River. Analysis of the state error covariance matrix for both rivers indicates that some reduction in the number of parameters associated with the difference equation formulated for mode 1 dynamics is possible.

The extended Kalman filter developed in this report provides a basis for projecting ice-affected streamflow at other gaging stations by adjusting filter parameters to site-specific conditions. The

filter can project daily mean flow during periods of ice effects by use of real-time climatological and hydrological data.

\section{LITERATURE CITED}

Bar-Shalom, Y., and Li Xiao-Rong (1993) Estimation and Tracking: Principles, Techniques, and Software. Boston, Massachusetts: Artech House.

Bozic, S.M. (1994) Digital and Kalman Filtering. New York: Halsted Press, 2nd edition.

Brown, R.G., and P.Y.C., Hwang (1997) Introduction to Random Signals and Applied Kalman Filtering. New York: John Wiley, 3rd edition.

Condes de la Torre, A. (1994) Operation of hydrologic data-collection stations by the U.S. Geological Survey in 1993. U.S. Geological Survey, Open-File Report 94-84.

Grewal, M. S., and A.P. Andrews (1993) Kalman Filtering Theory and Practice. Englewood Cliffs, New Jersey: Prentice Hall Information and System Sciences Series.

Holtschlag, D.J. (1996) A dynamical-systems approach for computing ice-affected streamflow. U.S. Geological Survey, Water-Supply Paper 2473.

Melcher, N.B., and J.F. Walker (1992) Evaluation of selected methods for determining streamflow during periods of ice effects. U.S. Geological Survey, Water-Supply Paper 2378.

Mendel, J.M. (1995) Lessons in Estimation Theory for Signal Processing, Communications, and Control. Englewood Cliffs, New Jersey: Prentice Hall PTR.

Novak, C.E. (1985) WRD data reports preparation guide. U.S. Geological Survey, Open-File Report $85-480$.

Weiss, M.A. (1996) Algorithms, Data Structures, and Problem Solving with C++. Menlo Park, California: Addison-Wesley Publishing. 


\section{APPENDIX A: SELECTED TIME SERIES FOR HYDROLOGICAL AND CLIMATOLOGICAL DATA}

St. John River at Dickey, Maine
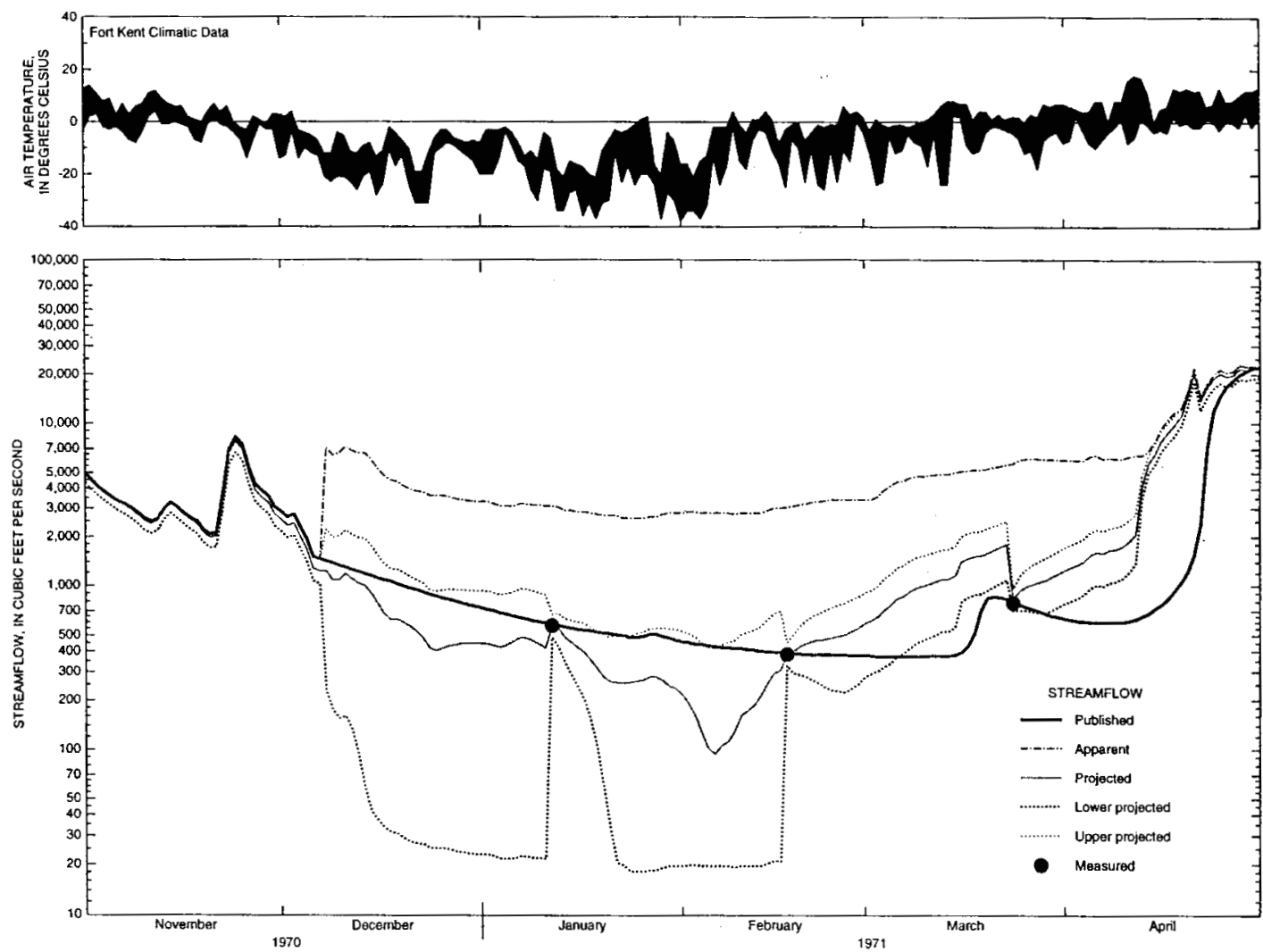

The scanned illustrations in this appendix may or may not print satisfactorily. If needed, paper copies of the entire report are available through the National Technical Information Service. See the inside cover of this report for ordering information. 

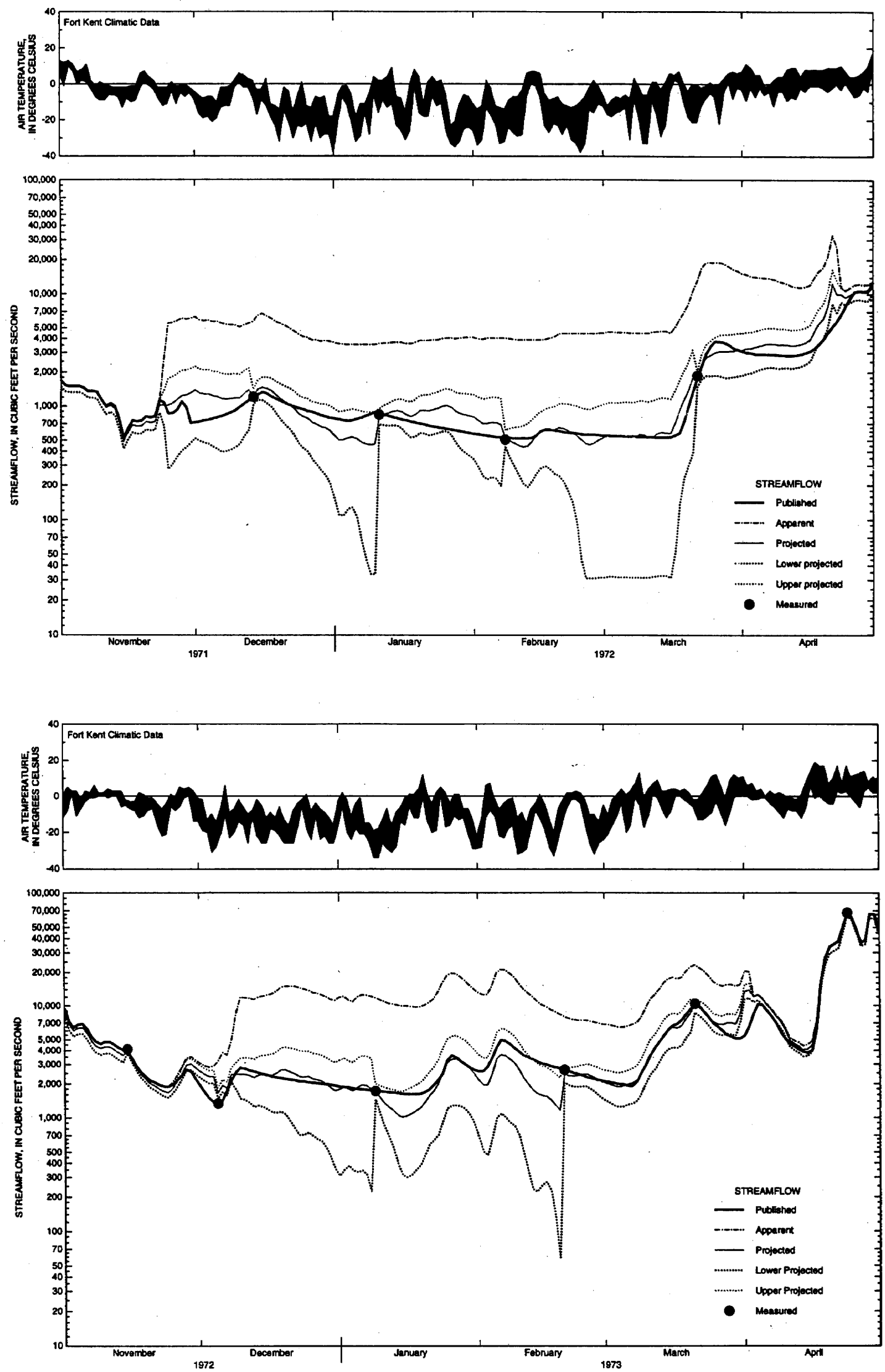

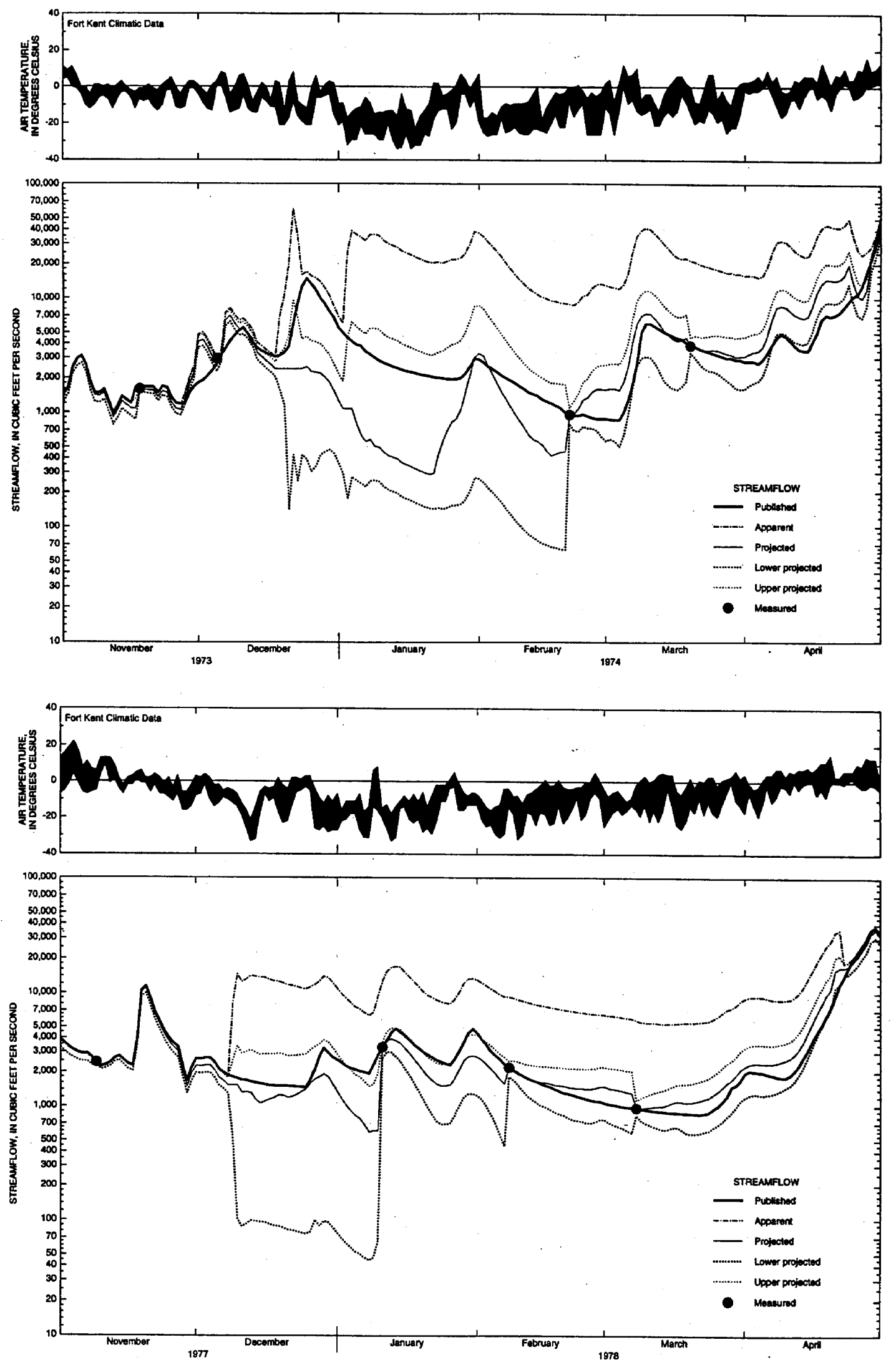

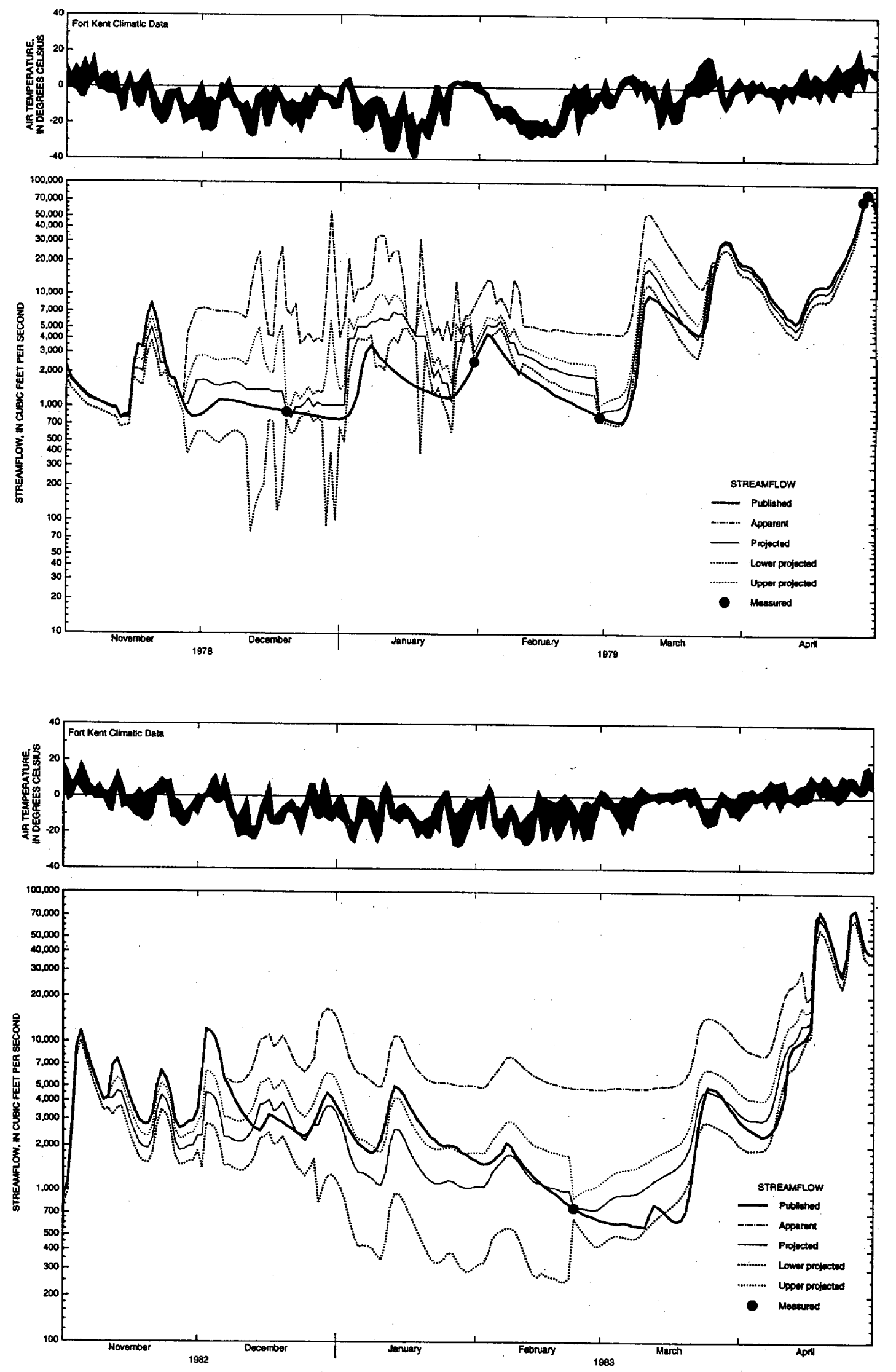

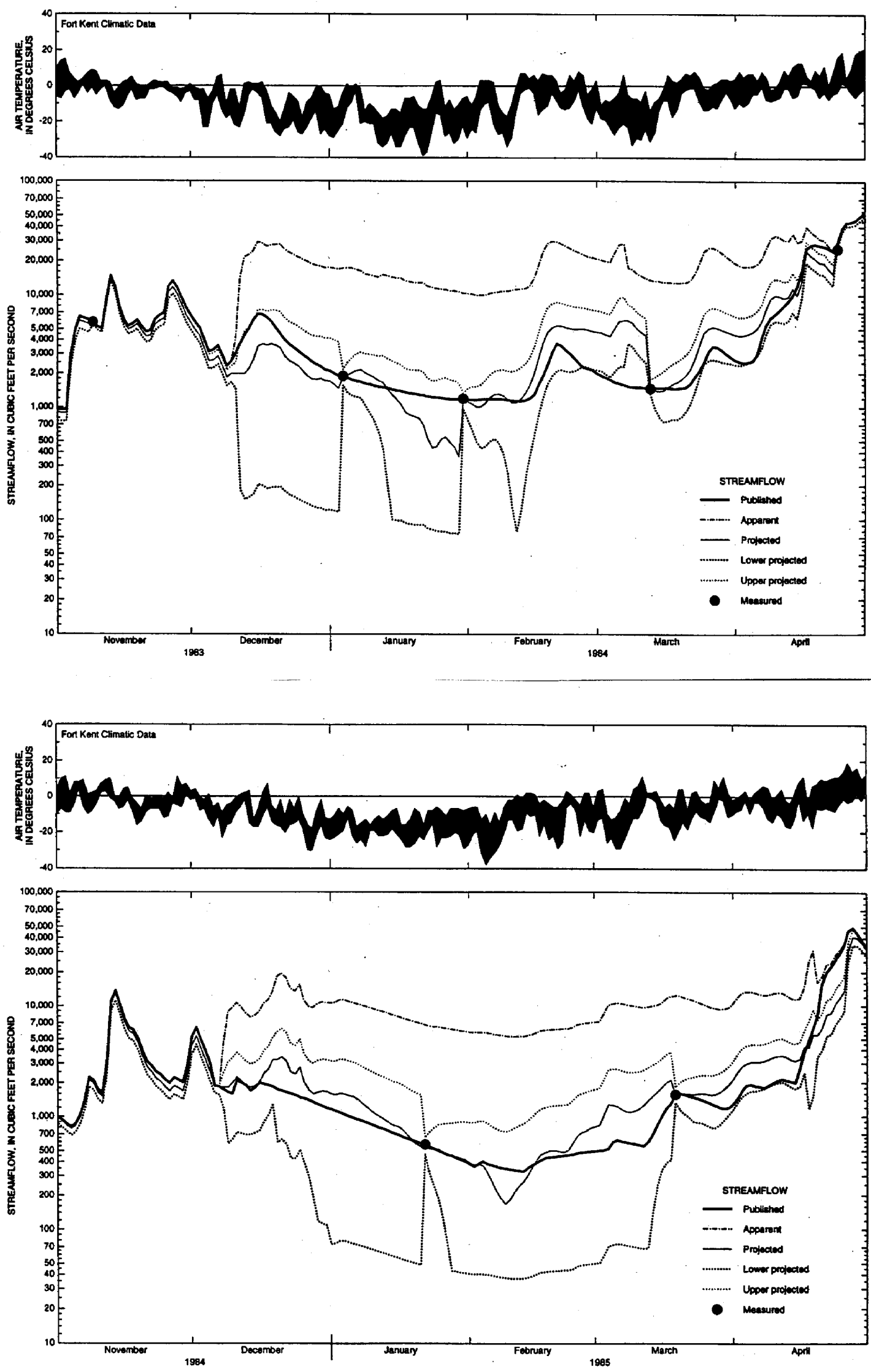

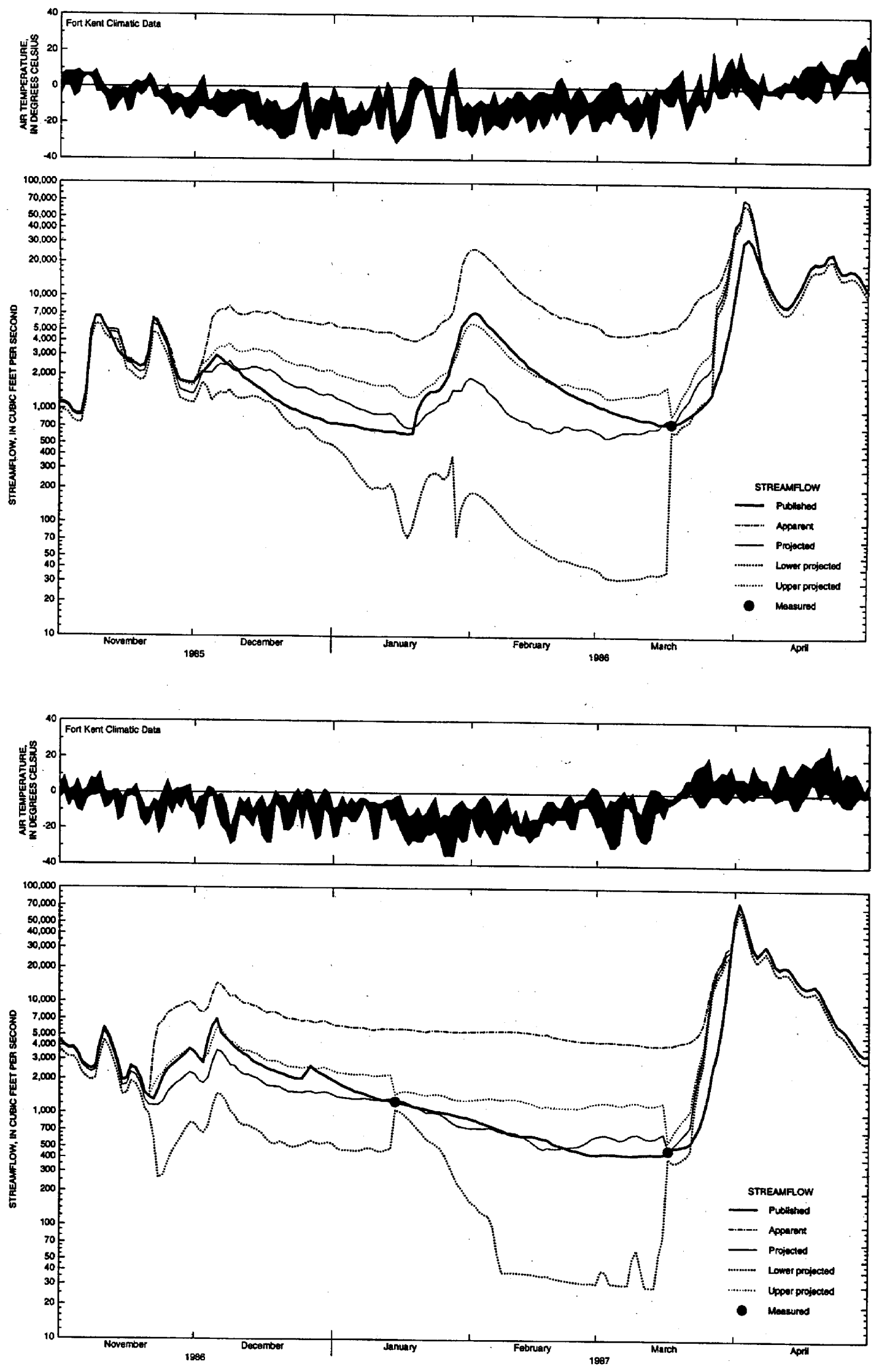

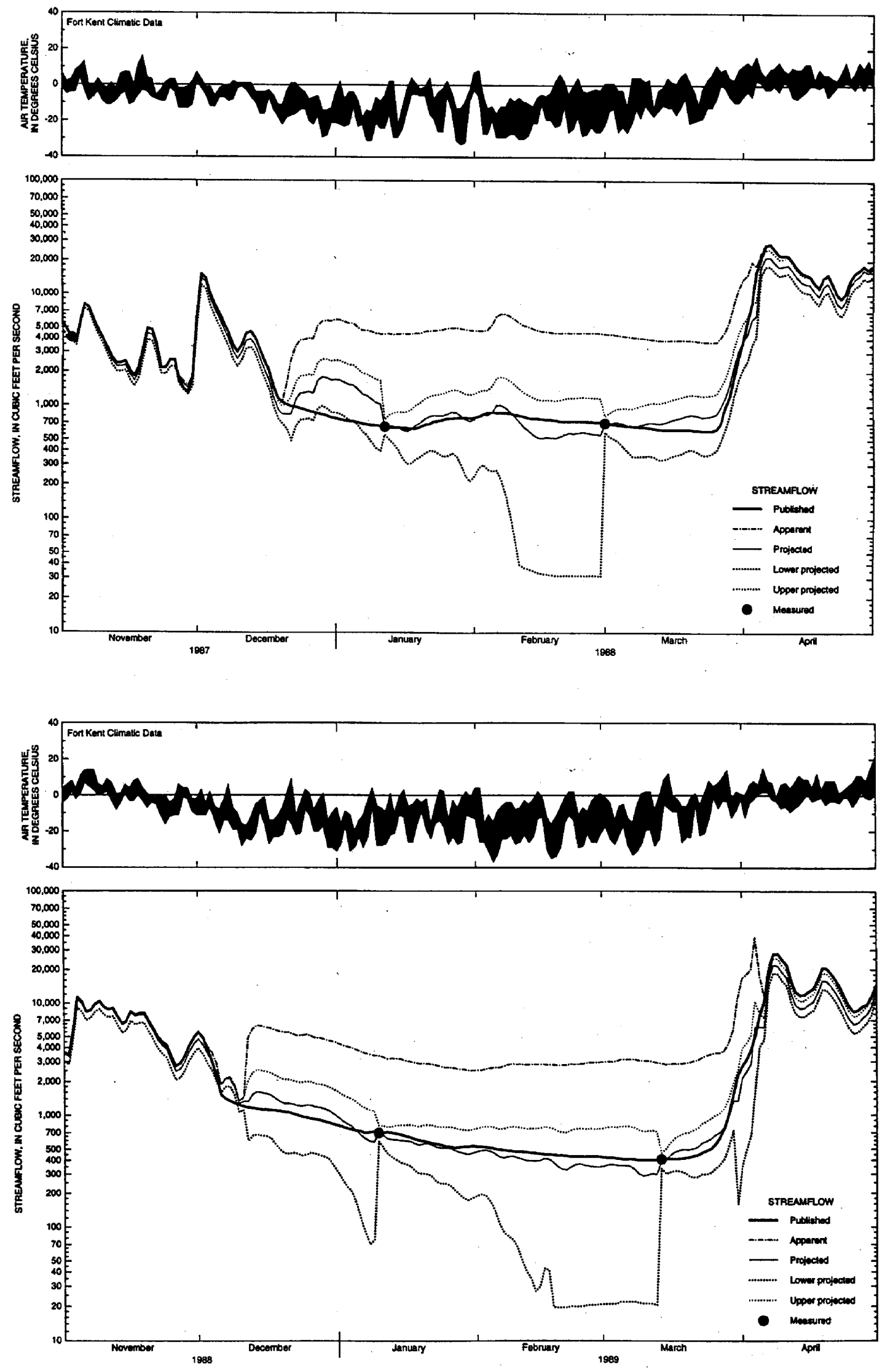

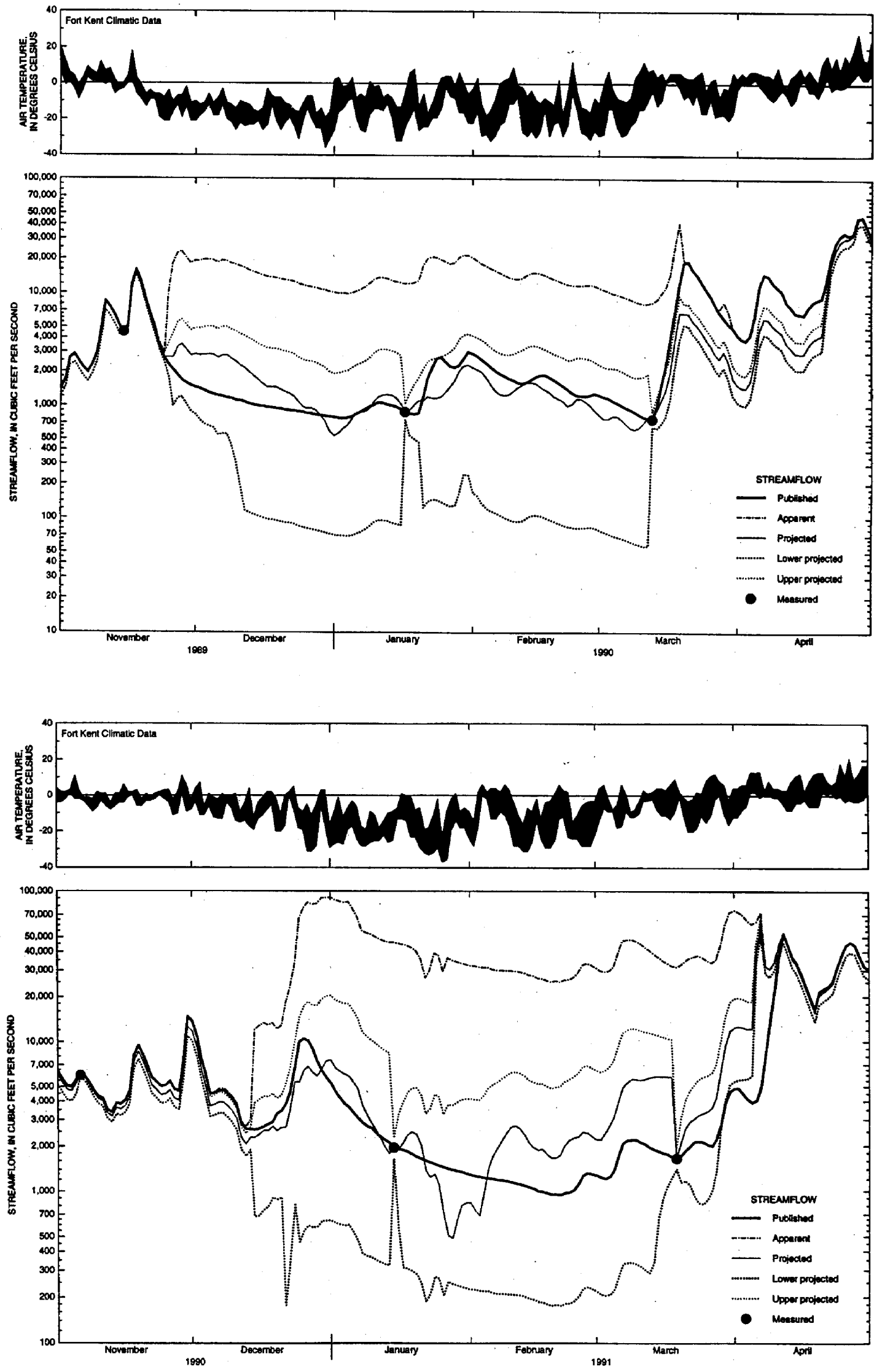

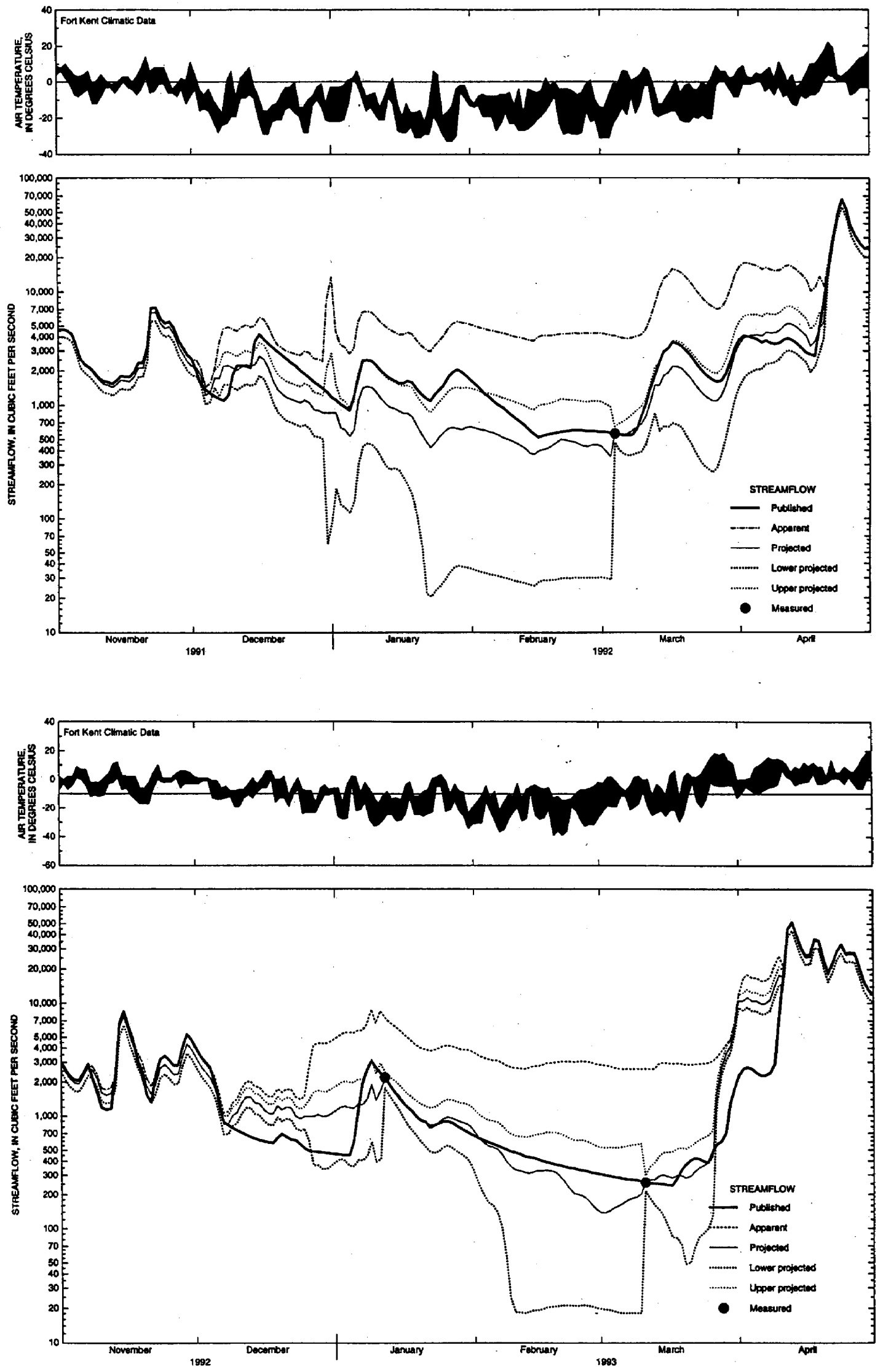
Platte River at North Bend, Nebraska
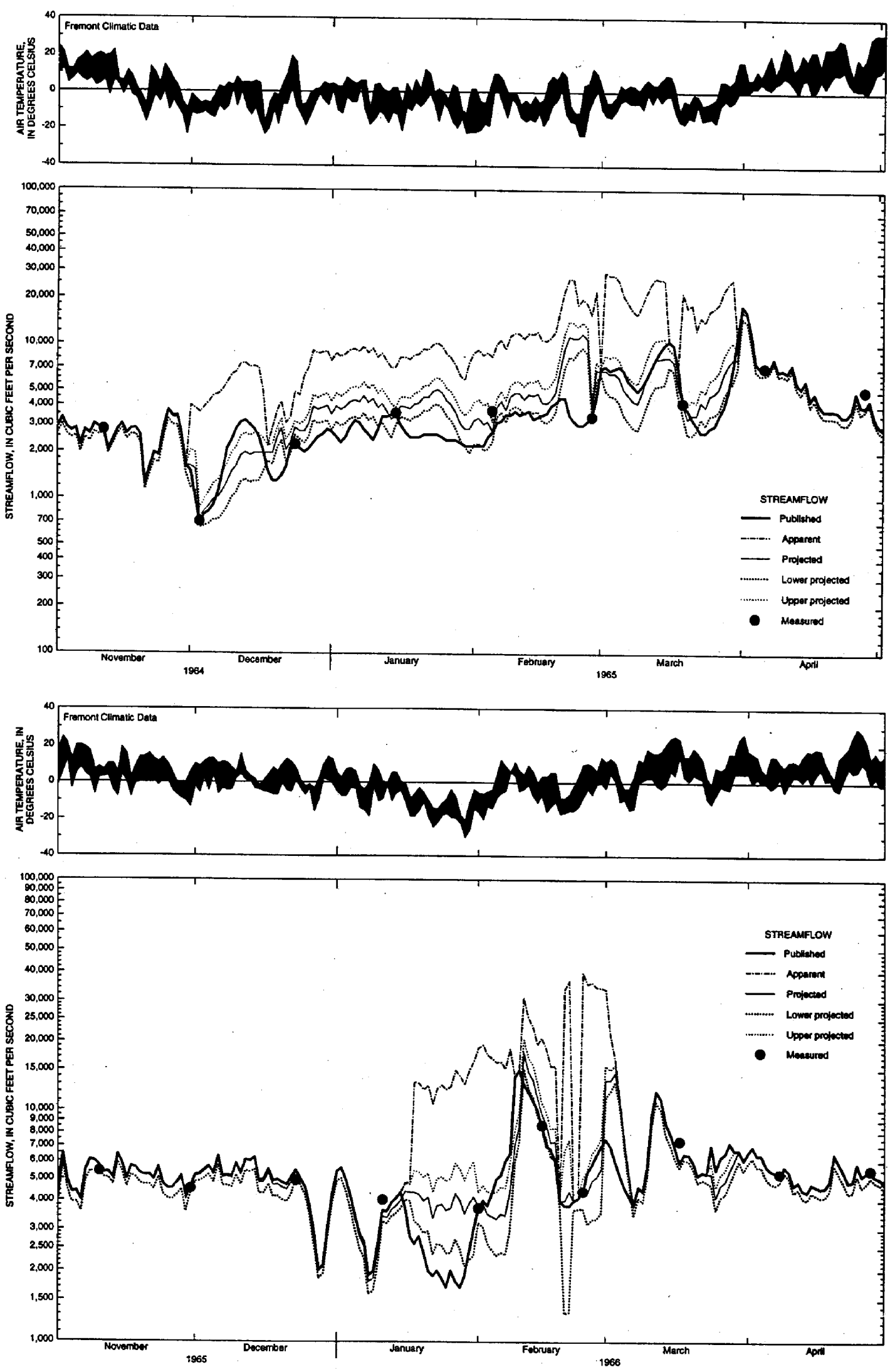

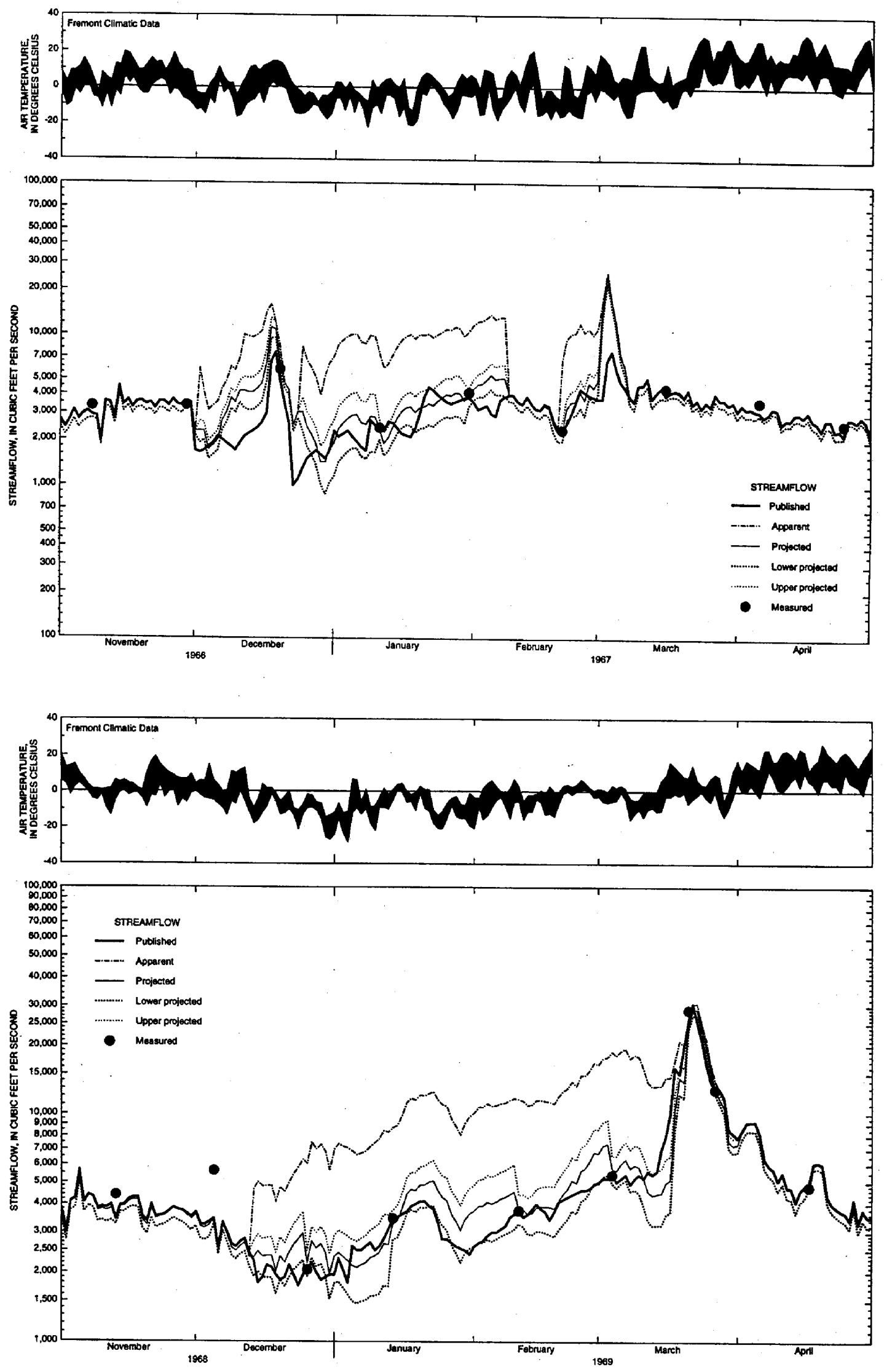

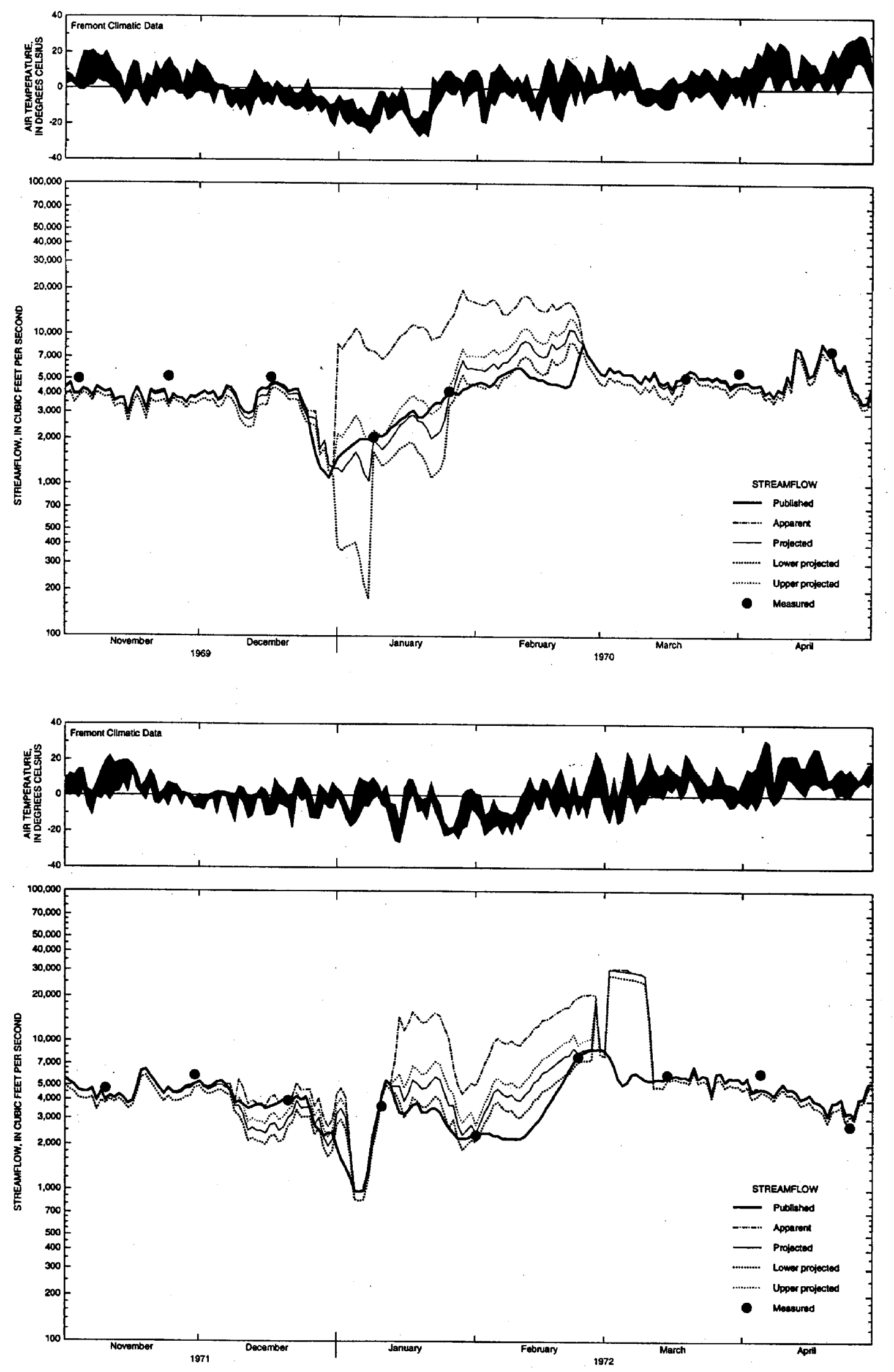

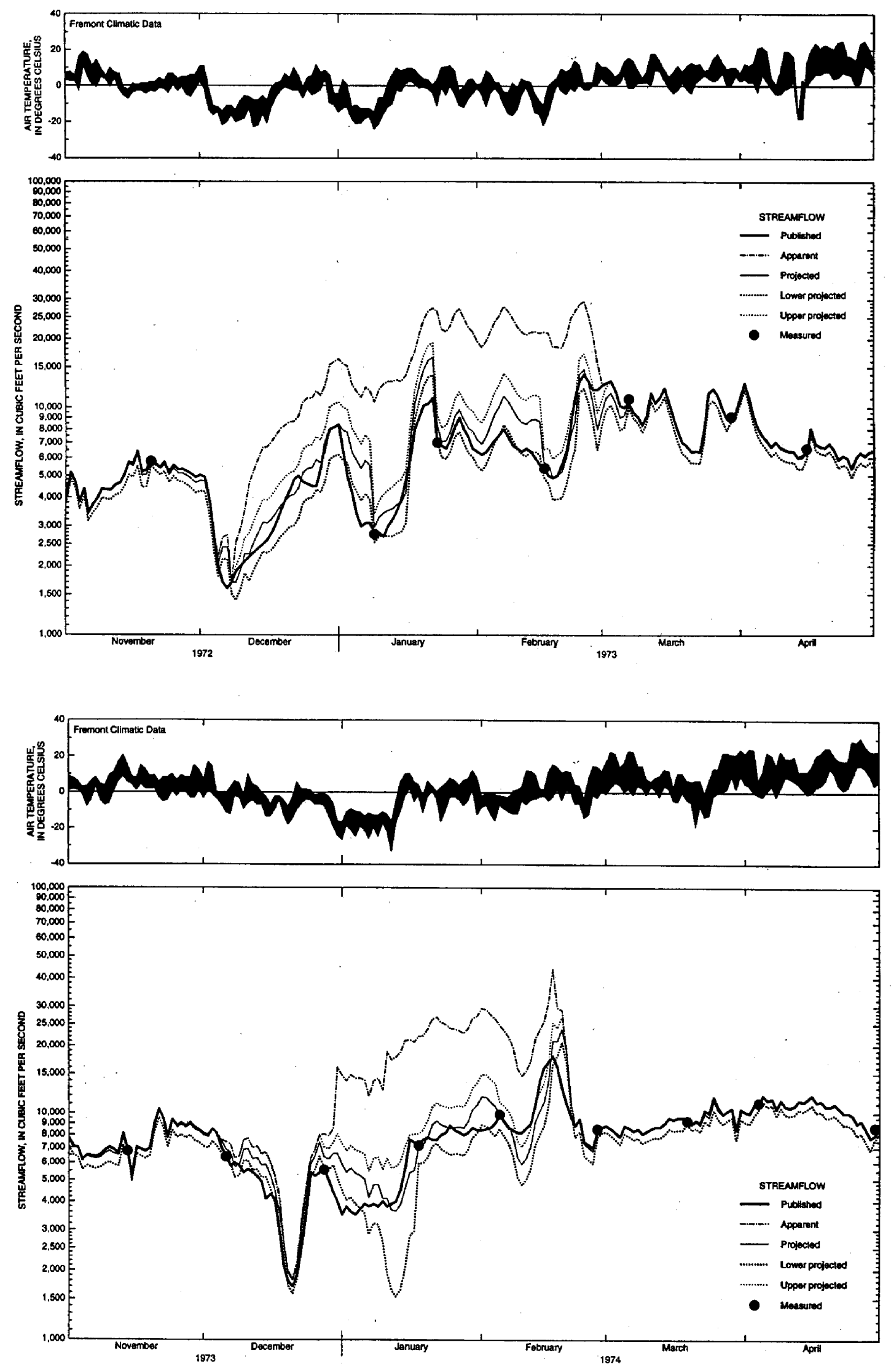

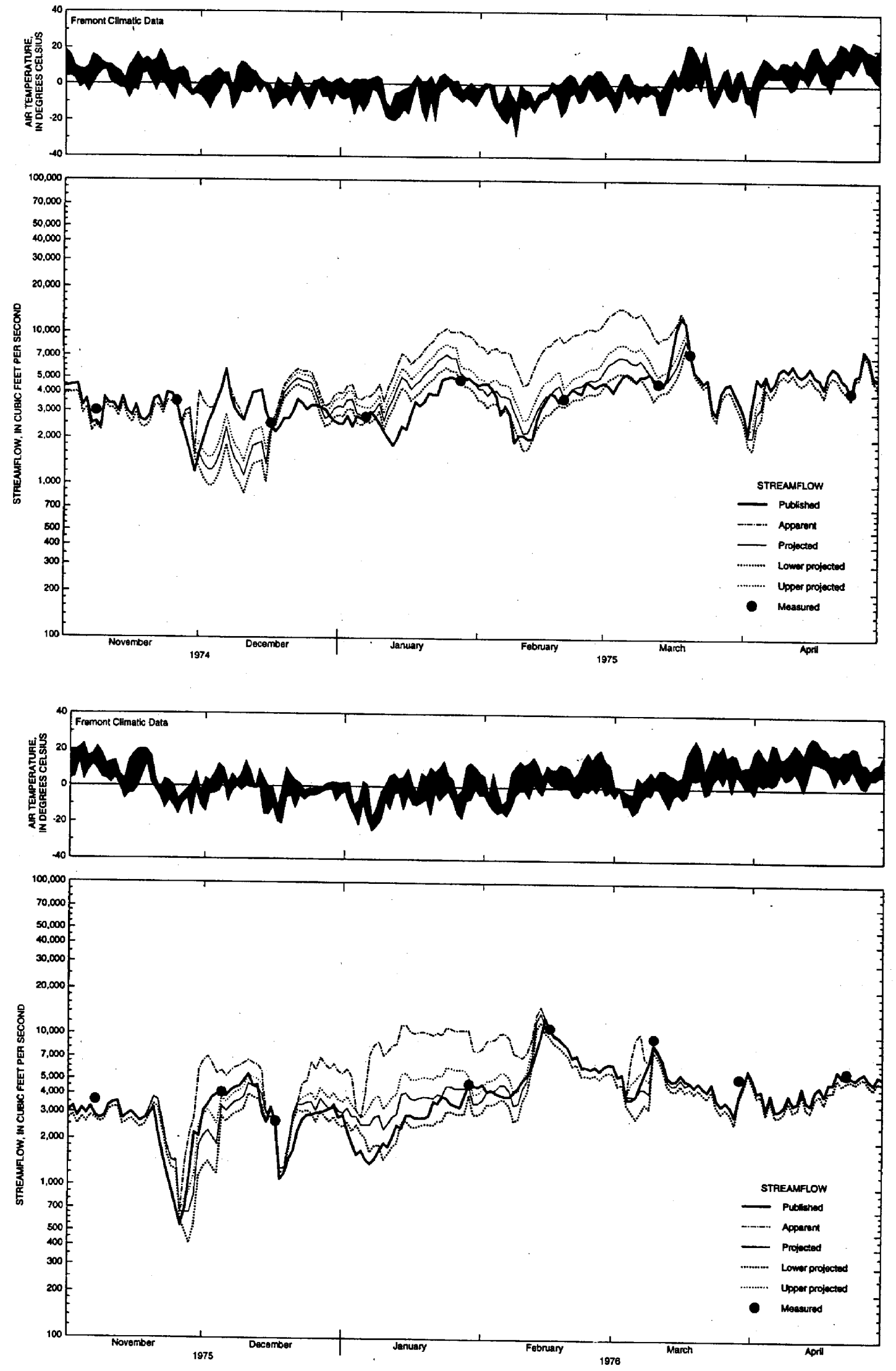

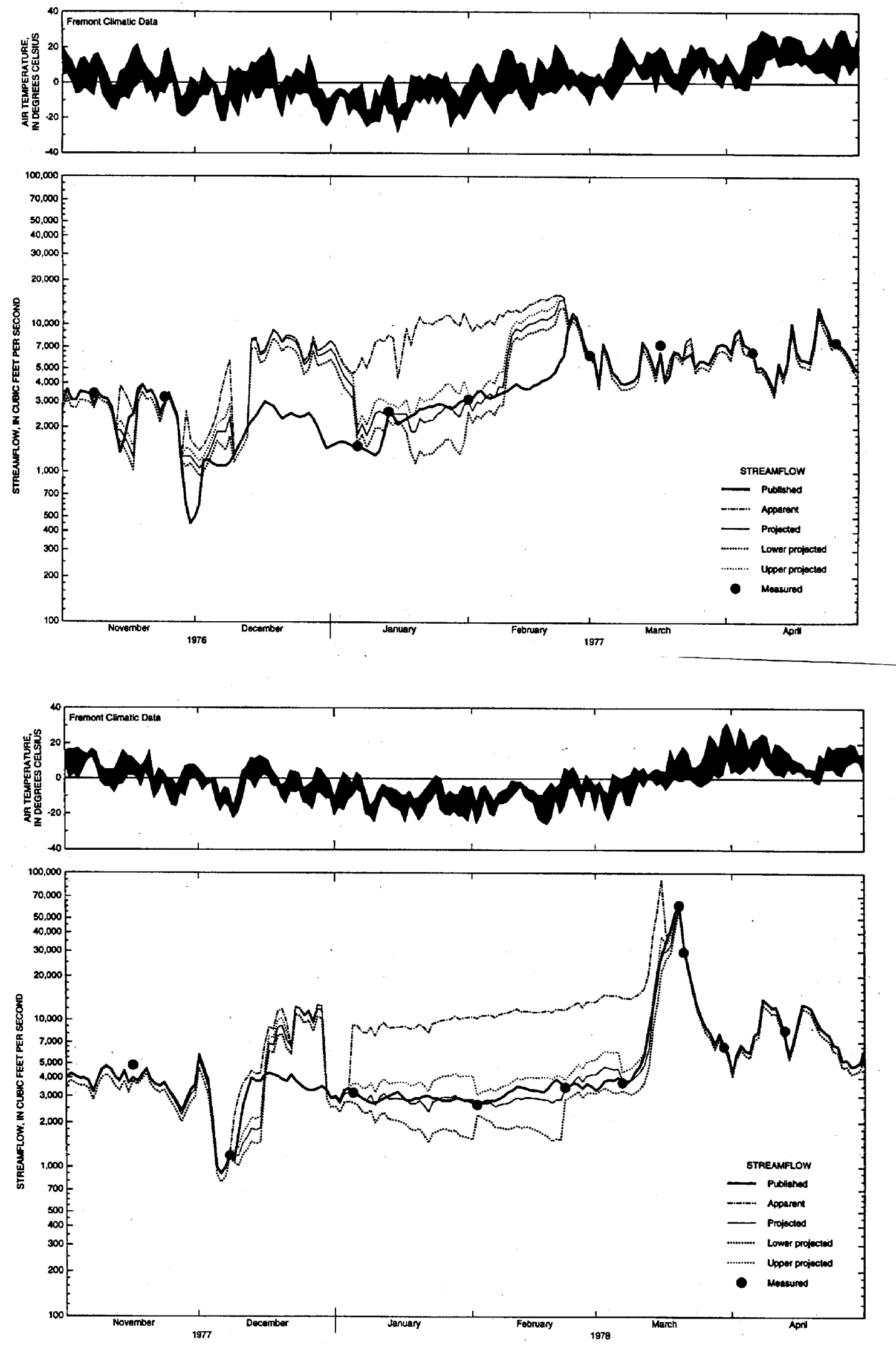

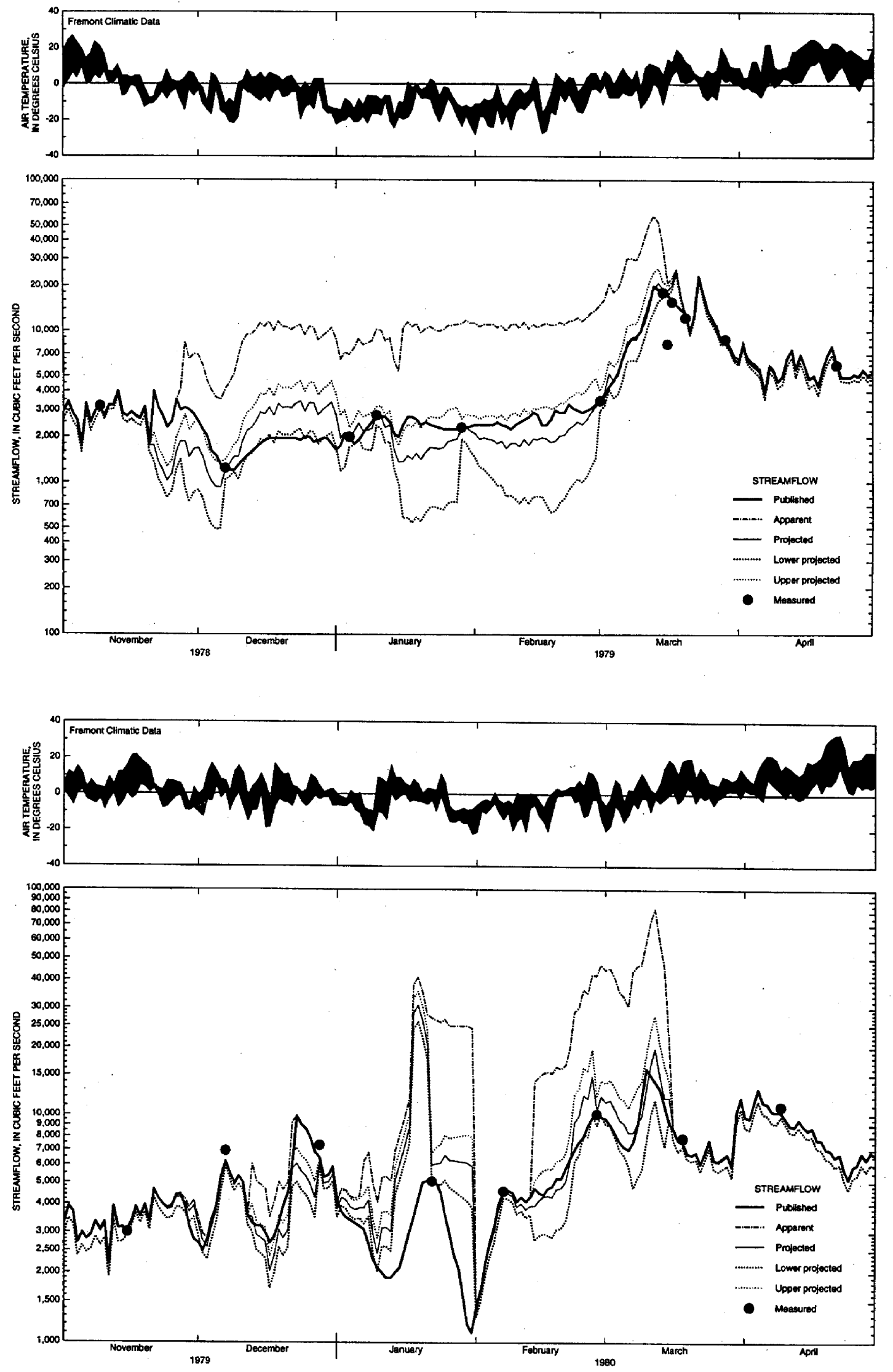

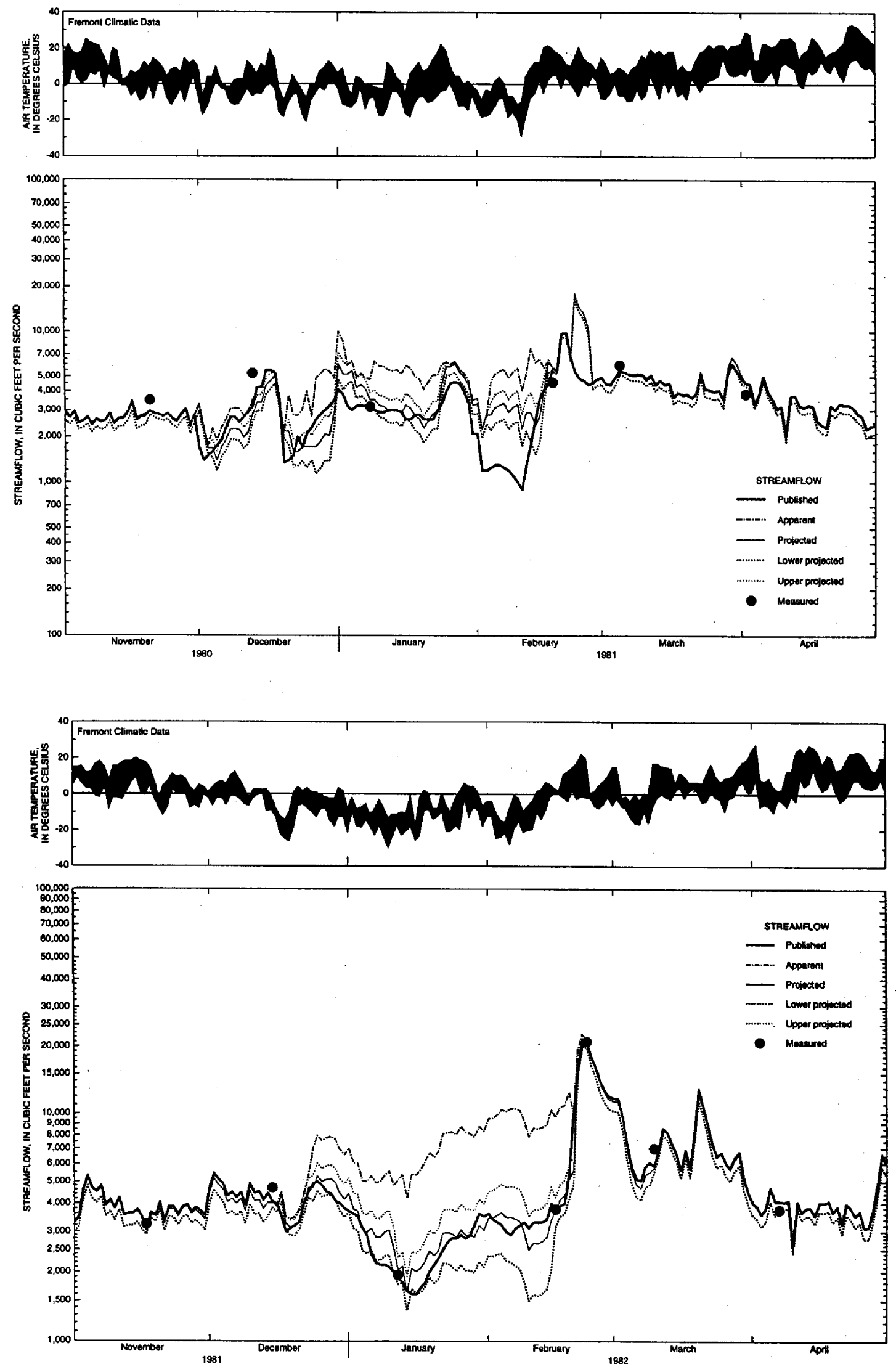

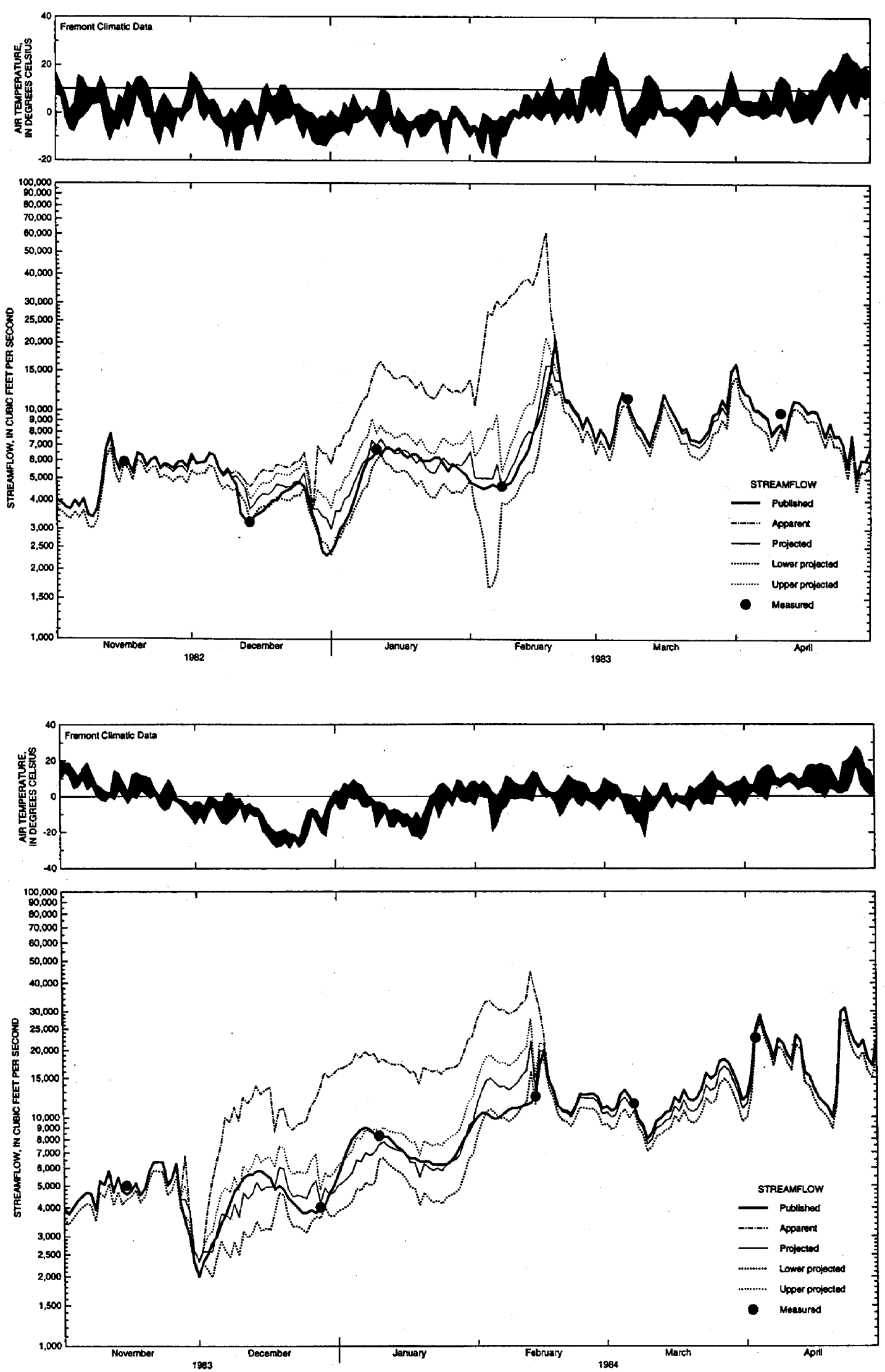

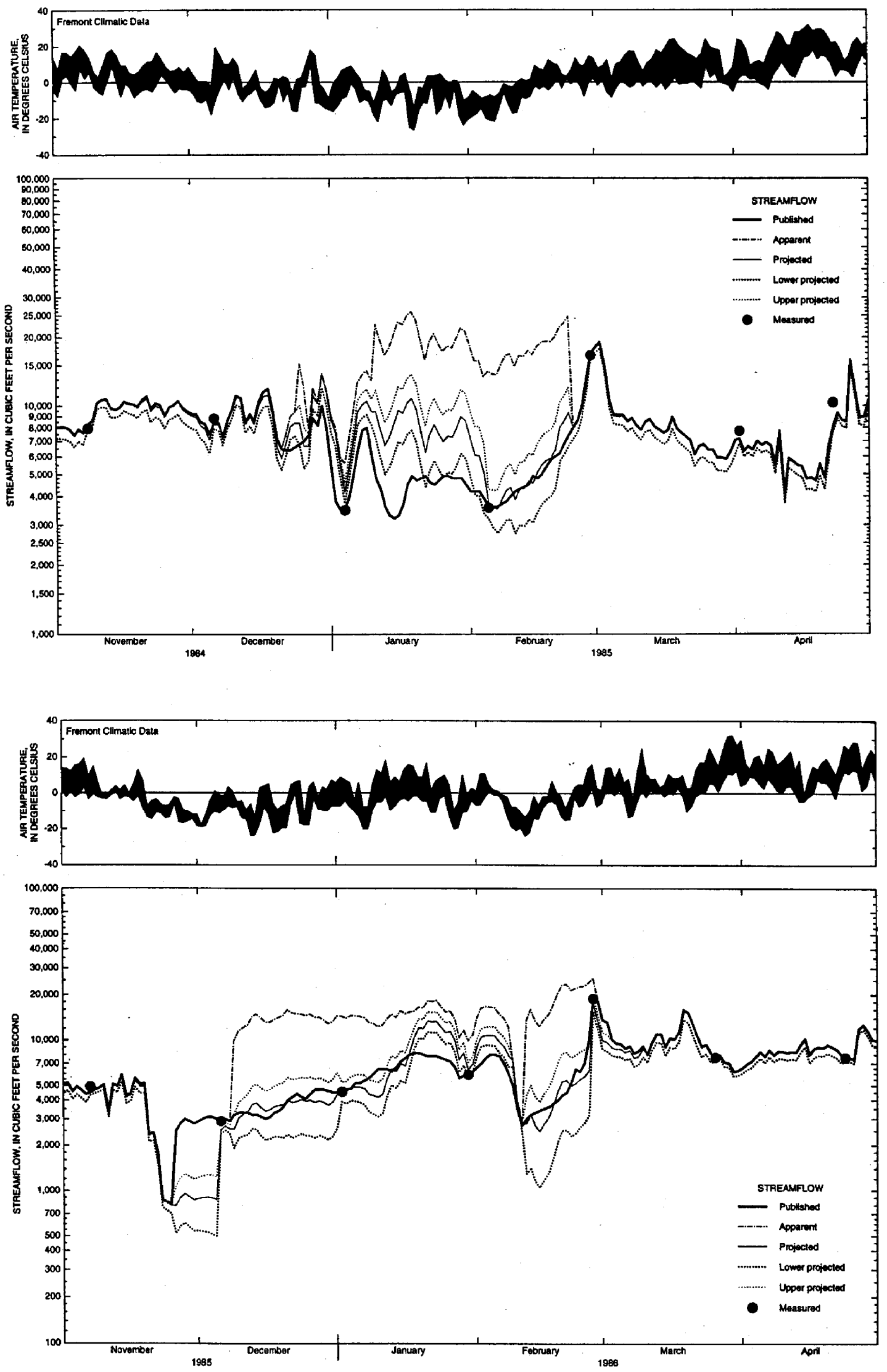

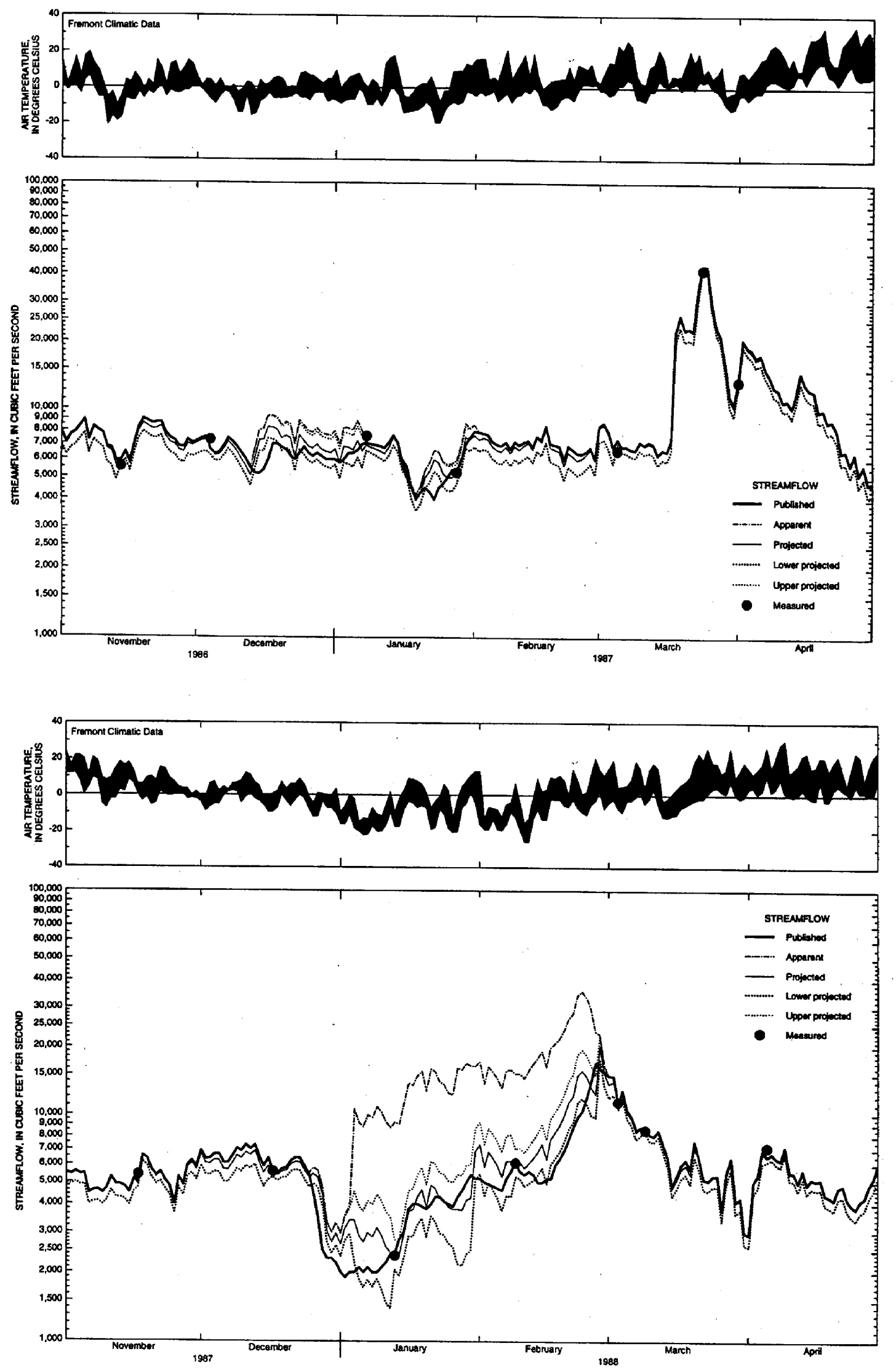

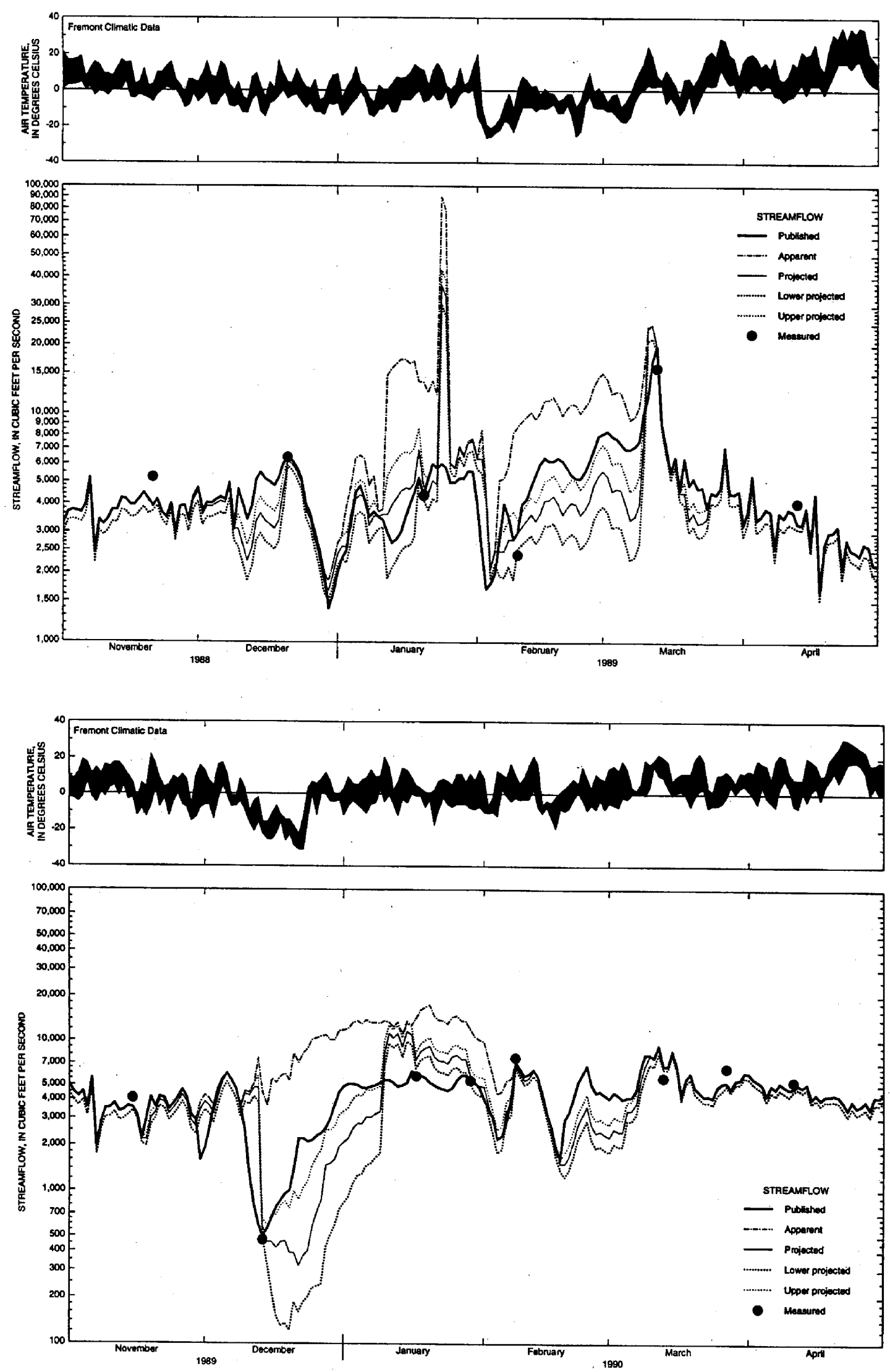

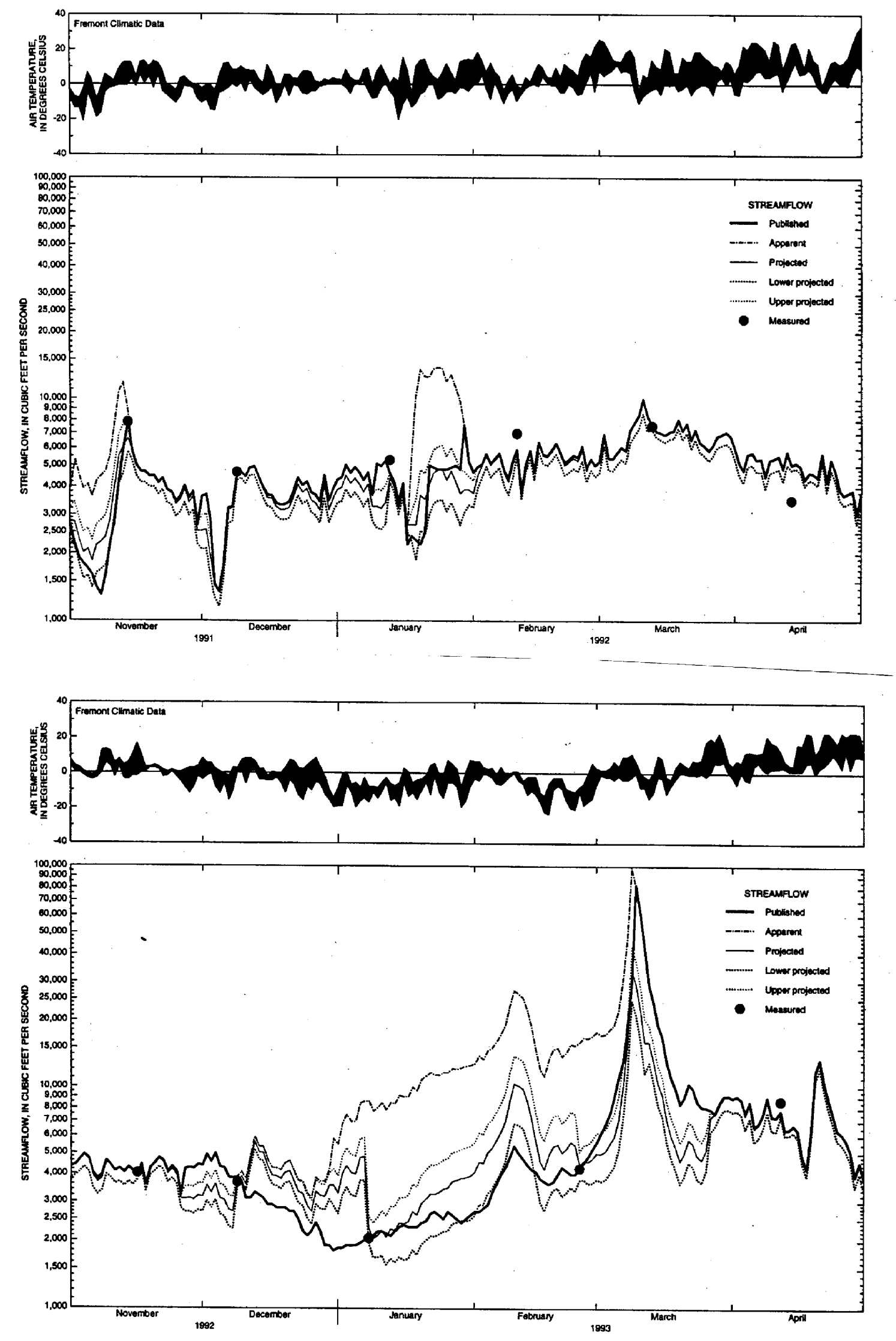

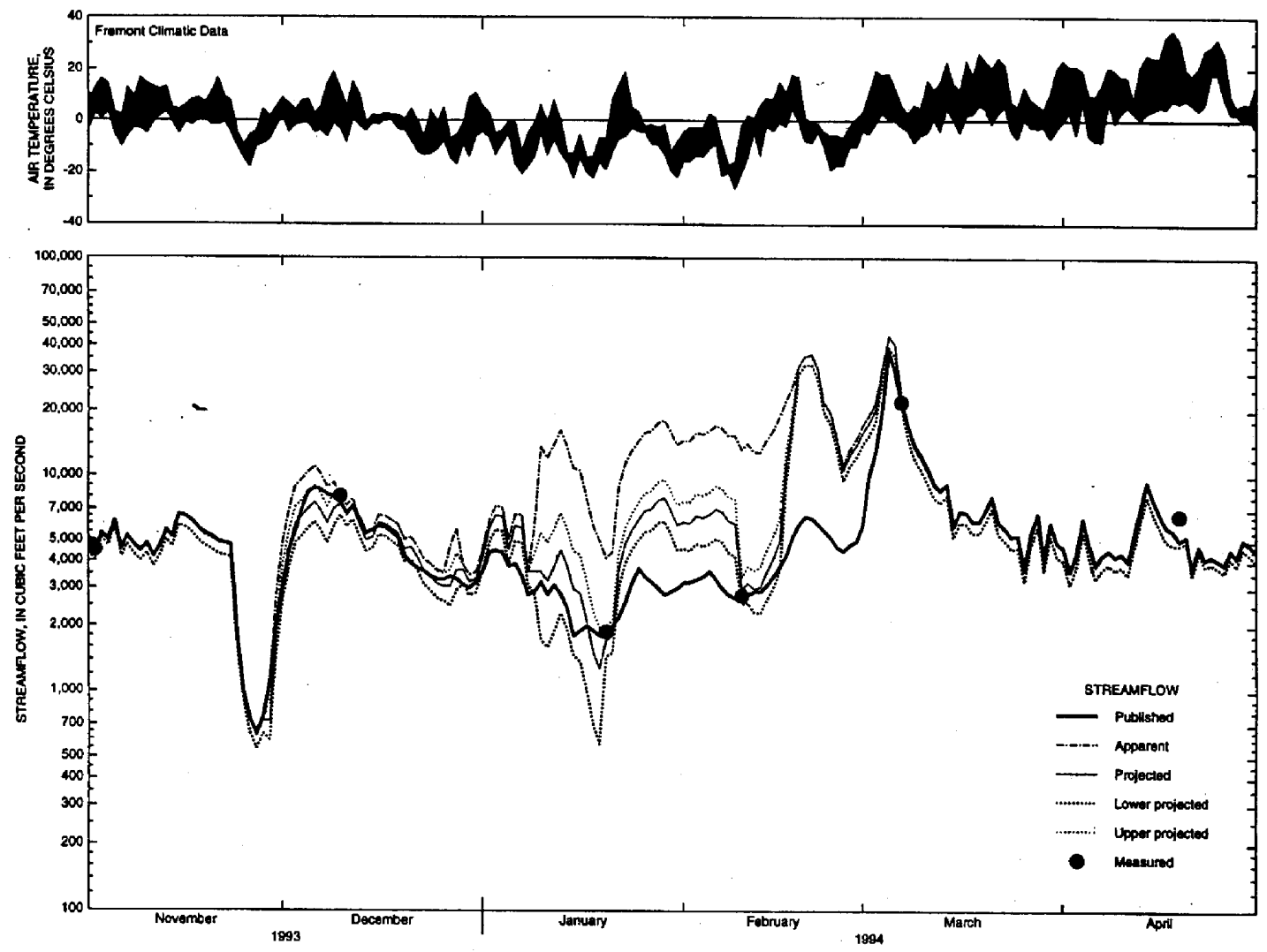
Public reporting burden for this collection of information is estimated to average 1 hour per response, including the time for reviewing instructions, searching existing data sources, gathering and maintaining the data needed, and completing and reviewing the collection of information. Send comments regarding this burden estimate or any other aspect of this collection of information, including suggestion for reducing this burden, to Washington Headquarters Services, Directorate for Information Operations and Reports, 1215 Jefferson Davis Highway, Suite 1204, Arlington, VA 22202-4302, and to the Office of Management and Budget, Paperwork Reduction Project (0704-0188), Washington, DC 20503.

\begin{tabular}{|l|l|l}
\hline 1. AGENCY USE ONLY (Leave blank) & $\begin{array}{l}\text { 2. REPORT DATE } \\
\text { December } 1997\end{array}$ & 3. REPORT TYPE AND DATES COVERED
\end{tabular}

\begin{tabular}{|l|l}
\hline 4. TITLE AND SUBTITLE & 5. FUNDING NUMBERS
\end{tabular}

Projecting Ice-Affected Streamflow by Extended Kalman Filtering

6. AUTHORS

David J. Holtschlag, Charles T. Parker, and Mohinder S. Grewal

\begin{tabular}{|l|l|}
\hline 7. PERFORMING ORGANIZATION NAME(S) AND ADDRESS(ES) & 8. \\
\hline
\end{tabular}

U.S. Geological Survey

8. PERFORMING ORGANIZATION REPORT NUMBER

Water Resources Division

6520 Mercantile Way, Suite 5

Lansing, Michigan 48911

9. SPONSORING/MONITORING AGENCY NAME(S) AND ADDRESS(ES)

10. SPONSORING/MONITORING AGENCY REPORT NUMBER

U.S. Army Cold Regions Research and Engineering Laboratory

72 Lyme Road

Hanover, New Hampshire 03755-1290

CRREL Report 97-8

11. SUPPLEMENTARY NOTES

12a. DISTRIBUTION/AVAILABILITY STATEMENT

12b. DISTRIBUTION CODE

Approved for public release; distribution is unlimited.

Available from NTIS, Springfield, Virginia 22161.

13. ABSTRACT (Maximum 200 words)

An extended Kalman filter was developed to automate the real-time projection of ice-affected streamflow, based on routine measurements of stage and air temperature and the relation between stage and flow during openwater conditions. The form accommodates three dynamic modes of ice effects: sudden formation-ablation, stable ice conditions, and final elimination. The filter was applied to historical data from two long-term streamflow-gaging stations. They were stable and parameters converged for both stations, producing estimates that were highly correlated with and linearly related to published streamflow values in a log-transformed metric. At St. John River at Dickey, Maine, logarithms of projected streamflow values were within $8 \%$ of the logarithms of published values $87.2 \%$ of the time and within $15 \%$ of published values $96.6 \%$ of the time during periods of ice effects. At Platte River at North Bend, Nebraska, logarithms of projected streamflow values were within $8 \%$ of the logarithms of published daily values $90.7 \%$ of the time and within $15 \%, 97.7 \%$ of the time during ice-affected conditions. This extended Kalman filter allows estimation of ice-affected streamflow at other gaging stations by adjusting filter parameters to site-specific conditions.

\begin{tabular}{|c|c|c|c|c|c|}
\hline Ice effects & \multicolumn{2}{|c|}{$\begin{array}{l}\text { Ice jams } \\
\text { Kalman filter }\end{array}$} & \multicolumn{2}{|l|}{$\begin{array}{l}\text { Platte River } \\
\text { St. John River }\end{array}$} & 16. PRICE CODE \\
\hline \multicolumn{2}{|c|}{$\begin{array}{l}\text { 17. SECURITY CLASSIFICATION } \\
\text { OF REPORT }\end{array}$} & $\begin{array}{l}\text { 18. SEC } \\
\text { OF }\end{array}$ & $\begin{array}{l}\text { CLASSIFICATION } \\
\text { AGE }\end{array}$ & $\begin{array}{l}\text { 19. SECURITY CLASSIFICATION } \\
\text { OF ABSTRACT }\end{array}$ & 20. LIMITATION OF ABSTRACT \\
\hline \multicolumn{2}{|c|}{ UNCLASSIFIED } & & ASSIFIED & UNCLASSIFIED & UL \\
\hline
\end{tabular}

NSN 7540-01-280-5500 